\begin{tabular}{|c|c|}
\hline Title & Optimization of combustion chamber geometry for natural gas engines with diesel micro-pilot-induced ignition \\
\hline Author(s) & Wang, Bin; Li, Tie; Ge, Linlin; Ogawa, Hideyuki \\
\hline Citation & $\begin{array}{l}\text { Energy conversion and management, 122, 552-563 } \\
\text { https://doi.org/10.1016/.enconman.2016.06.027 }\end{array}$ \\
\hline Issue Date & 2016-08-15 \\
\hline Doc URL & http:/hdl.handle.net/2115//1310 \\
\hline Rights & $\begin{array}{l}\text { (2) 2016. Ins manuscript version is made avallable under the CC-BY-IVC-IVD } 4.0 \text { IIcense } \\
\text { http://creativecommons.org/icenses/by-nc-nd/4.0/ }\end{array}$ \\
\hline Rights(URL) & http://creativecommons.org/icenses/by-nc-nd/4.0/ \\
\hline Type & article (author version) \\
\hline File Information & Revised Manuscript-clean version.pdf \\
\hline
\end{tabular}

Instructions for use 


\title{
Optimization of combustion chamber geometry for natural gas engines with
} diesel micro-pilot-induced ignition

\author{
Bin Wang ${ }^{1,2}$, Tie $\mathrm{Li}^{1,2 *}$, Linlin $\mathrm{Ge}^{1}$, Hideyuki Ogawa ${ }^{3}$ \\ 1. State Key Laboratory of Ocean Engineering, Shanghai Jiao Tong University \\ 2. Collaborative Innovation Center for Advanced Ship and Deep-Sea Exploration, Shanghai \\ Jiao Tong University \\ 3. Faculty of Engineering, Hokkaido University \\ *Corresponding Address: 800 Dongchuan Rd., Shanghai, PR China, 200240; \\ Tel.: (86)21-3420-8348; E-mail: litie@sjtu.edu.cn
}

\begin{abstract}
Smokeless, low nitrogen oxides (NOx), and high thermal efficiency have been achieved through the lean-burn concept for natural gas engine with diesel micro-pilot-induced ignition (MPII). However, the combustion chamber is usually not specialized for natural gas combustion, and increases in the unburned hydrocarbon (HC) and carbon monoxide (CO) emissions are still a challenge for this type of engines. This paper describes optimization of the combustion chamber geometry to reduce the $\mathrm{HC}$ and $\mathrm{CO}$ emissions and improve the combustion efficiency in the MPII natural gas engine. The 3-D computational fluid dynamics (CFD) simulation model coupled with a chemical reaction mechanism is described. The temporal development of the short-pulsed diesel spray in a high pressure constant-volume vessel is measured and used to calibrate the spray model in the CFD simulation. The simulation models are validated by the experimental data of the in-cylinder pressure trace, apparent heat release rate (AHRR) and exhaust gas emissions from a single-cylinder MPII natural gas engine. To generate the various combustion chamber geometries, the bowl outline is parameterized by the two cubic Bezier
\end{abstract}


24 curves while keeping the compression ratio constant. The available design space is explored by

25 the multi-objective non-dominated sorting genetic algorithm II (NSGA- II) with

26 Kriging-based meta-model. With the optimization, the HC and CO emissions are reduced by

$2756.47 \%$ and 33.55\%, respectively, while the NOx emissions, the maximum rate of pressure rise

28 and the gross indicated thermal efficiency that are employed as the constraints are slightly

29 improved. Finally, the mechanism of the reduction in HC and CO emissions with the optimized

30 combustion chamber geometry is investigated and discussed in details.

32 KEY WORDS: natural gas, diesel micro-pilot-induced ignition, combustion chamber geometry,

33 HC/CO emissions, model-based optimization 


\section{Introduction}

Due to the higher energy conversion efficiency than other power plants, the compression ignition (CI) diesel engines are widely adopted as the primary propulsion device for ships [1, 2]. In order to restrict the harmful emissions from the commercial vessels, especially in the designated emission control areas (ECAs), Tier III emission standard regulated by International Maritime Organization (IMO) will be implemented in 2016 [3]. Compared to IMO Tier I , this stage requires a reduction of the nitrogen oxides (NOx) by $80 \%$. Stricter limitations are also progressively applied on the sulfur oxides (SOx) and particulate matter (PM) emissions. To meet the upcoming emission regulations, the alternative fuels together with advanced clean combustion concepts will play an increasingly important role in the future transportation systems with diesel engine as power source [4-6].

With development and maturity of the shale gas technology, the natural gas production in America has increased substantially up to 31,345 billion cubic feet in 2014, which is $16.8 \%$ larger than that in 2010 [7, 8]. Foreseeably, natural gas is becoming one of the promising alternative fuels in the field of energy since it is available in greater quantities with lower cost. In addition, natural gas also has the advantage of lower harmful emissions in comparison with the traditional petroleum fuels (i.e., gasoline and diesel). Natural gas is mainly consisted of methane

$51\left(\mathrm{CH}_{4}\right)$. With a promotion of natural gas application as fuels, the carbon dioxide $\left(\mathrm{CO}_{2}\right)$ and PM emissions can be suppressed, as a result of the higher hydrogen to carbon $(\mathrm{H} / \mathrm{C})$ atom ratio in natural gas. The research octane number (RON) of natural gas is up to about 130 [9]. Hence, the higher compression ratio can be applied in the natural gas engines so as to obtain the better thermal efficiency. Furthermore, natural gas has the wider flammable limit. Based on the 
constant volume combustion chamber, Liao et al. [10] measured the lean flammable limit and upper flammable limit for the natural gas/air mixtures were $5 \%$ and $15.6 \%$, respectively, of natural gas by volume. Therefore, the lean-burn combustion concept with increasing boost pressure is available for the natural gas engines in order to obtain the excellent comprehensive characteristics of the fuel economy, power performance and exhaust gas emissions.

Recently, several researchers have investigated the various applications of natural gas in the internal combustion engines with a focus on the characteristics of the performance, combustion and exhaust gas emissions. Due to the low self-ignitability, natural gas has been usually utilized in the spark ignition (SI) engines [11]. In general, this kind of the technical scheme was adopted to replace the gasoline engine in some automobiles because of the cheaper price and lower emissions [12]. Nonetheless, Ogawa et al. [13] reported that the advantages of natural gas would not be completely explored in the SI engines and the reduction of engine power performance was remarkable. As to the CI engines, the dual fuel operating mode of natural gas coupled with the high reactivity fuel (e.g., diesel fuel) provides the novel opportunity and application mode $[13,14]$. Under the high compression ratio conditions, the micro-pilot diesel was injected into the cylinder to ignite the premixed natural gas. Takahashi et al. [15] proposed a dual fuel combustion strategy of natural gas/diesel in the marine engine with a pre-combustion chamber. The small amount of diesel fuel, which is about $1 \%$ of total input energy, was injected into the pre-combustion chamber. The natural gas in the pre-combustion chamber was ignited firstly, then the flame propagated into the main cylinder to burn the lean pre-mixture of the natural gas and air. The released energy by those small quantity of diesel fuel as an ignition source was 
ignition mode is more reliable and stable even under the high compression ratio and ultra-lean mixture conditions. Furthermore, the technique that the diesel fuel is directly injected in the cylinder will be more flexible than that of the above-mentioned pre-combustion chamber scheme. In the gas engine KU30GA, the natural gas as a main fuel was supplied from the intake manifold system, while the micro-pilot diesel fuel was directly injected in the cylinder to control the combustion phasing [16]. Besides the simpler arrangement and quicker launch, it is also a practical way to take advantage of natural gas more efficiently in the CI engines.

Natural gas engines with the micro-pilot diesel ignition can significantly reduce NOx and PM emissions [13, 17]. However, the unburned hydrocarbon (HC) and carbon monoxide (CO) emissions are obviously higher than that of the normal diesel mode [18]. Yousefi et al. [5] established a multi-dimensional computational fluid dynamics (CFD) model coupled with the chemical kinetics mechanisms to examine the effect of various premixed fuels including natural gas and equivalence ratios on the performance and emissions of a dual-fuel pilot diesel ignition engine. Liu et al. [19] presented the effects of pilot fuel quantity on the emissions characteristics of a natural gas/diesel dual fuel engine. Under the lean premixed conditions, NOx emissions can be reduced by $30 \%$ in comparison to the baseline diesel engine. In addition, the authors claimed that the unburned methane accounts for about $90 \%$ of the $\mathrm{HC}$ emissions, while the CO emissions are originated mainly from the quenching of the lean premixed natural gas mixture. Ishiyama et al. [20] studied the different diesel pilot injection timings for improvement of the dual-fuel combustion with a lean natural gas-air mixture. As to the single-stage injection experiments, the results showed that the injection timings from $-20^{\circ}$ to $-10^{\circ} \mathrm{CA}$ ATDC produce the low $\mathrm{HC} / \mathrm{CO}$ emissions. The earlier injection at $-35^{\circ} \mathrm{CA}$ ATDC is advantageous to reduce NOx; but it 
deteriorates the $\mathrm{HC} / \mathrm{CO}$ emissions. The two-stage pilot injections with an early first injection and

101 a moderately advanced second injection enable the improved thermal efficiency and reduced

102 exhaust emissions. Based on a single-cylinder direct injection CI engine, Abdelaal and Hegab

103 [17] focused on the partly-cooled exhaust gas recirculation (EGR) to achieve higher thermal

104 efficiency and lower exhaust emissions, particularly at part loads. Dual-fuel mode with moderate

105 EGR, such as 5\%, 10\%, and 20\%, exhibits the thermal efficiency comparable to the conventional

106 diesel mode. The larger reduction of NOx can be achieved, when the higher percentage of EGR

107 is employed. The application of EGR to dual-fuel mode slightly reduces the HC and CO

108 emissions, but these emissions were still considerably higher than that of the conventional diesel

109 engine.

110 The dual fuel engines in the previous studies are mostly realized by modifying the

111 conventional diesel engines with the natural gas introduced into the intake ports. While the

112 combustion chamber geometry plays a critical role in the combustion, so far few researches

113 focus on the effect of combustion chamber geometry on the performance and exhaust gas

114 emissions of the duel fuel natural gas engine. Such a study is particularly necessary for the MPII

115 engines with the natural gas as the main fuel and the micro-pilot diesel primarily as an ignition

116 source, since the combustion in the MPII engines could be totally different from the

117 conventional diesel diffusive combustion. Therefore, it is necessary to explore the potential of

118 optimized combustion chamber for the MPII concept to reduce the HC and CO emissions and

119 improve the energy conversion efficiency.

120 The objective of this study is to investigate the potential of optimizing the combustion

121 chamber geometry to reduce the $\mathrm{HC}$ and $\mathrm{CO}$ emissions and further improve the energy 
conversion efficiency of the MPII natural gas engine. The paper is organized as follows: the experimental setups of the bench test of an MPII natural gas engine and a spray visualization

124 system are firstly described. Then, the numerical models based on 3D computational fluid dynamics for the MPII engine are formulated and calibrated against the spray visualization and engine bench test data, followed by the model-based optimization methodology for the combustion chamber design. After the presentation of the results and detailed discussion, finally,

128 the major conclusions are summarized.

\section{Experimental setup}

\subsection{Engine bench test}

132 The schematic of the engine bench test is shown in Figure 1, and the specifications of the single

133 cylinder MPII natural gas engine for the present study are listed in Table 1. The detailed

134 information of the engine bench test system can be found in the previous publication [13], here only a brief description is given. Natural gas was introduced into the engine from the intake manifold. The micro-pilot diesel was directly injected into the cylinder by a common rail fuel injection system with 120 MPa injection pressure. The diesel injector has nine holes with the orifice diameter of $0.16 \mathrm{~mm}$ and the spray included angle of $152^{\circ}$. The injection duration was $2.53^{\circ} \mathrm{CA}$, resulting in an injection quantity of $4.0 \times 10^{-3} \mathrm{ml} / \mathrm{cycle}$. An injection timing of $-7.30^{\circ} \mathrm{CA}$ ATDC, which was an optimized one with a consideration of the thermal efficiency as

141 high as possible and the maximum rate of pressure rise below $1.2 \mathrm{MPa} /{ }^{\circ} \mathrm{CA}$, was employed to calibrate the simulation models for optimization of the combustion chamber. For the data at

143 other injection timings, one may refer to the previous publication [13]. The supercharger driven 
144 by an electric motor, and EGR system connected with a diesel particulate filter (DPF) and an

145 EGR inter-cooler were adopted in the system. In order to eliminate the influences from the

146 pumping process, the exhaust back pressure in the exhaust manifold was automatically regulated

147 by an electric controlled throttle to keep the same as the intake manifold pressure.

148

149

150

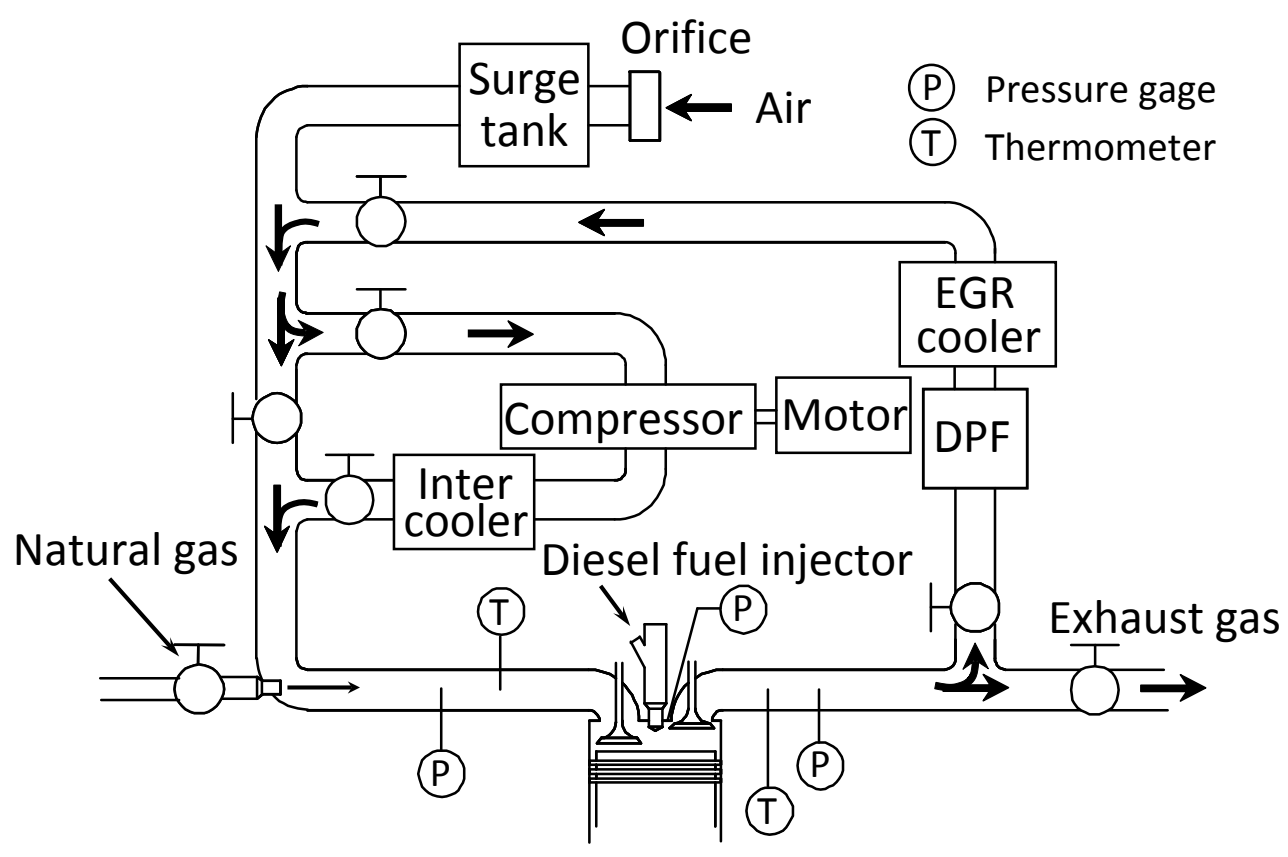

Fig. 1. Schematic diagram of the MPII natural gas engine.

Table 1. MPII natural gas engine specifications.

\begin{tabular}{cc}
\hline Engine configuration & Single cylinder, four-stroke, direct injection \\
\hline Bore $\times$ Stroke & $98 \times 110 \mathrm{~mm}$ \\
Displacement & $0.83 \mathrm{~L}$ \\
Compression ratio & $16.5: 1$ \\
Engine speed & $1200 \mathrm{rpm}$ \\
Equivalent ratio of natural gas & 0.513 \\
Indicated mean effective pressure (IMEP) & $8.0 \mathrm{bar}$ \\
Intake oxygen concentration & $21 \%$ \\
Swirl ratio & 1.8 \\
Intake valve closing (IVC) & $-140^{\circ} \mathrm{CA} \mathrm{ATDC}$ \\
Exhaust valve opening (EVO) & $150^{\circ} \mathrm{CA} \mathrm{ATDC}$ \\
Injection pressure & $120 \mathrm{MPa}$ \\
Diesel injection duration & $2.53^{\circ} \mathrm{CA}$ \\
Start of injection & $-7.30^{\circ} \mathrm{CA} \mathrm{ATDC}$ \\
Diesel fuel volume per shot & $4.0 \times 10^{-3} \mathrm{ml} / \mathrm{cycle}$ \\
\hline
\end{tabular}




\subsection{Spray visualization test}

As shown in Figure 2, a Z-type experimental setup for the high-speed Shadowgraph imaging technique was established for the spray characterization to calibrate the spray model. It consisted of a Xenon lamp (Newport 66984), a pinhole, two concave mirrors and a high-speed CMOS video camera (NAC Memrecam HX-6). The imaging speed of 50000 fps (frame per second) was used to record the temporal and spatial development of the micro-pilot diesel spray under the non-evaporating conditions. The same injector as that in the engine bench tests was used and a specially designed cap was install on the injector tip to enable only one hole fuel injection by a high-pressure common-rail system.

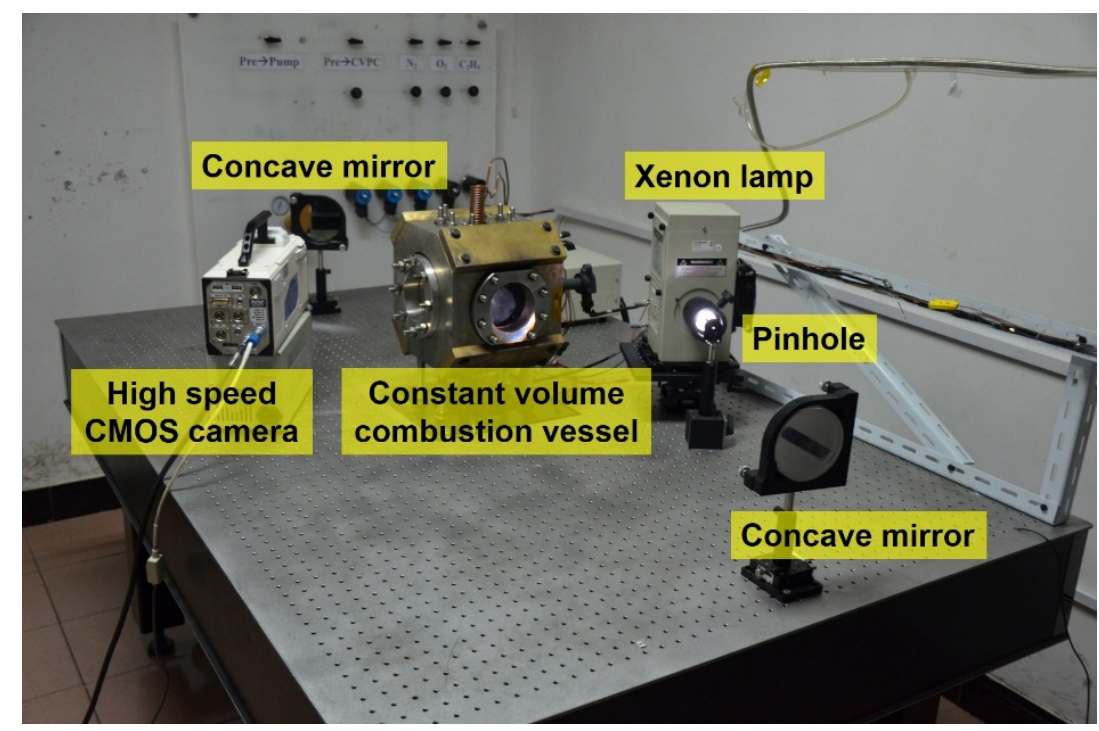

Fig. 2. Experiment setup of Shadowgraph imaging technique for the micro-pilot diesel spray under the non-evaporating conditions.

\section{The fuel injection and ambient conditions in this study are given in Table 2. The high} pressure constant-volume vessel was charged with nitrogen $\left(\mathrm{N}_{2}\right)$ to the targeted ambient density for the test of non-evaporating diesel spray. The method proposed by Naber and Siebers [21] was adopted to determine the tip penetration length of the diesel spray. 
Table 2. Test conditions for the non-evaporating diesel fuel spray.

\begin{tabular}{cc}
\hline Ambient gas density $\rho_{a}$ & $20 \mathrm{~kg} / \mathrm{m}^{3}$ \\
Ambient gas temperature $T_{a}$ & $298 \mathrm{~K}$ \\
Injection pressure $P_{i n j}$ & $120 \mathrm{MPa}$ \\
Injection duration $t_{d}$ & $0.55 \mathrm{~ms} / \mathrm{shot}$ \\
Fuel temperature $T_{f}$ & $298 \mathrm{~K}$ \\
\hline
\end{tabular}

170

171 3. Numerical model and validation

172

173

174

175

176

177

178

180

181

182

183

184

185

186

187

\subsection{D CFD modeling}

The 3D CFD numerical model for the engine combustion simulation was established based on CONVERGE ${ }^{\mathrm{TM}}$ software package. In order to implement the detailed chemistry calculations and analyses during the combustion simulation process, the detailed transient chemistry solver, termed as SAGE, was incorporated into the 3D CFD model. The standard CHEMKIN format files used to define the chemical mechanisms and thermodynamic properties can be directly resolved by SAGE solver. In the model, the premixed natural gas oxidation process was represented using the GRI-Mech 3.0 chemical kinetic mechanism [22], while the chemical reactions of diesel fuel were represented by those of the surrogates developed by Farrel et al. [23]. Finally, the merged chemical kinetic mechanism consisted of 76 species and 464 reactions. Renormalization Group (RNG) $k$ - $\varepsilon$ turbulence model based on the Reynolds Averaged Navier-Stokes (RANS) theory was used to simulate the turbulent flow within the combustion chamber [24]. Compared with the standard $k-\varepsilon$ turbulence model, the turbulence dissipation rate affected by the velocity dilatation and the variation of kinematic viscosity was taken into account in the RNG $k$ - $\varepsilon$ turbulence model [25]. The combustion model proposed by Kong et al. [26] was employed in this study to determine the kinetic and turbulent time scales in the simulation. 

and Rayleigh-Taylor (KH-RT) hybrid model using the physical properties of DF2. The droplet

190 collision processes were simulated by the No Time Counter (NTC) method [27], Frossling

191 correlation was used to calculate the vaporization rate of liquid droplets [28]. Although no

192 droplet impingements would occur because of the short-pulsed injection in this study, the wall

193 film model proposed by O’Rourke and Amsden was employed in the simulation [29]. Woschni's

194 model was employed to simulate the heat transfer in this study [30]. The extended Zel'dovich

195 mechanism was utilized to describe the NOx formation [31]. The prediction of soot formation

196 and oxidation was not considered in the present study, since the amount of soot formed in the

197 MPII natural gas engine was not discernable in the previous experimental study [13].

Due to the symmetry of the combustion chamber and injector with the nine nozzle holes, a

$40^{\circ}$ sector mesh was used to reduce the computational burden. The base grid was set to $1.4 \mathrm{~mm}$.

Figure 3 shows the computational mesh used in this study, and the simulation was carried out

with the closed system from IVC at $-140^{\circ} \mathrm{CA}$ ATDC to EVO at $150^{\circ} \mathrm{CA}$ ATDC.

202

203

204

205

206

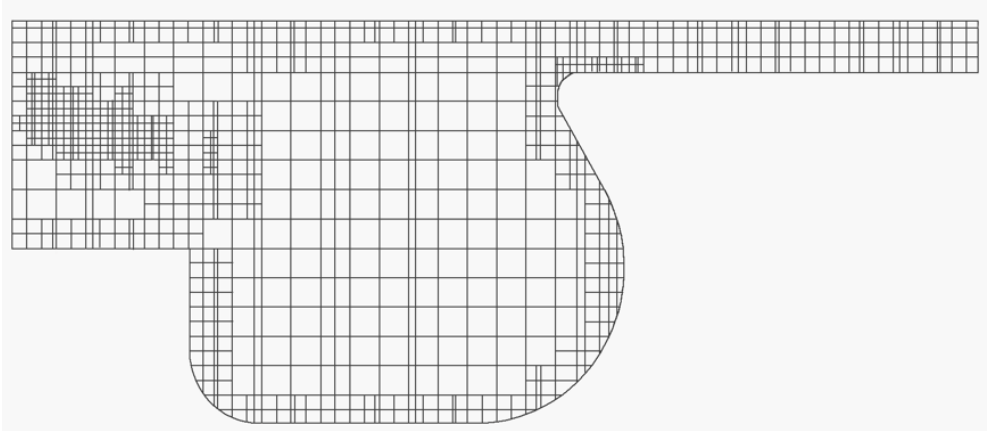

Fig. $3.40^{\circ}$ sector computational mesh of the baseline engine.

In order to simplify the grid generation for moving boundaries, an adaptive mesh refinement (AMR) algorithm was used to obtain the improved accuracy with acceptable computational cost. Furthermore, the local mesh embedding technique, such as in the near-injector region, was 

present study.

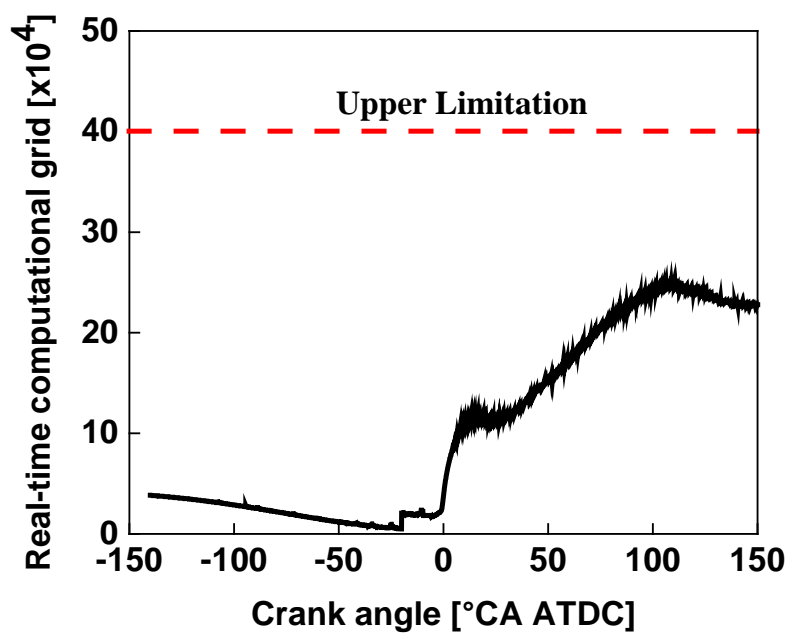

211

\subsection{Spray model validation}

Fig. 4. The evolution of the real-time computational grid number with crank angle during the entire combustion simulation procedure.

It is well known that the temporal and spatial development of diesel spray has the critical impacts on the combustion characteristics and emissions formation of diesel engines. Although the injection amount of the micro-pilot diesel is small, the accuracy of spray model is also considered to be crucial for the MPII natural gas engine. In this work, the calibration of the micro-pilot diesel spray model was conducted based on the experimental results of the non-evaporating diesel spray in the high pressure constant-volume vessel.

Figure 5(a) shows the high speed Shadowgraph images of the diesel spray under the high ambient pressure and room temperature conditions. Given at the top of each image is the time after start of the fuel injection (ASOI). Since the same 9-hole injector as used in the engine 
bench tests was employed here, a specially designed cap was mounted at the tip of the nozzle to

block the interference from the sprays issued by other holes, and only one spray plume is imaged in Figure 5(a).

Under the same conditions as the spray test, the micro-pilot diesel spray in the high pressure constant-volume vessel was simulated using CONVERGE ${ }^{\mathrm{TM}}$ software package. The spray angle was kept at $15^{\circ}$ based on the experimental results. In the simulation, the threshold which is $99.9 \%$ of the fuel mass fraction remains was used to determine the spray tip penetration length. The internal flow was not considered in the simulation, so we simplified the geometry by neglecting the nozzle tip or using a virtual position where fuels were issued out. Figure 5(b) shows the temporal development of the simulated short-pulsed spray under the same injection and ambient conditions. A reasonable agreement between the simulation and experiments can be found in

236 Figure 5.

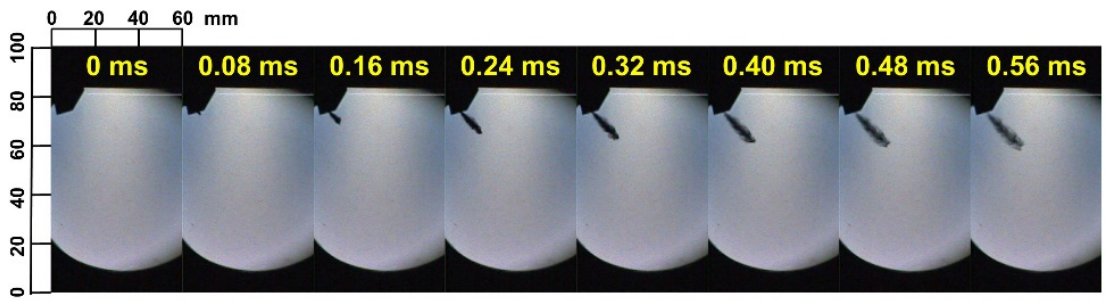

(a)

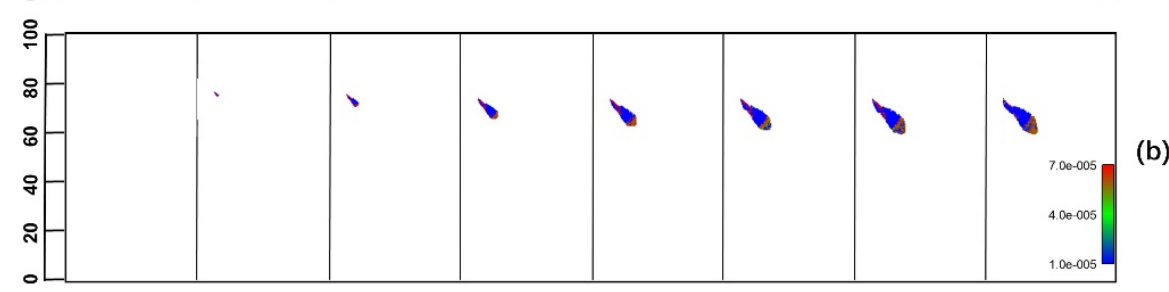

Fig. 5. The temporal development of short-pulsed diesel spray under the non-evaporating conditions: (a) high speed Shadowgraph images, (b) CFD simulation results $\left(t_{d}=0.55 \mathrm{~ms}\right.$, $P_{i n j}=120 \mathrm{MPa}, T_{a}=298 \mathrm{~K}, \rho_{a}=20 \mathrm{~kg} / \mathrm{m}^{3}$ ).

The comparison of experiment and simulation results for micro-pilot diesel spray tip penetration is shown in Figure 6. Through tuning the relative coefficients in the KH-RT hybrid breakup model, the temporal development of micro-pilot diesel spray in the simulation is well 

can be applied to the followed engine CFD simulation.

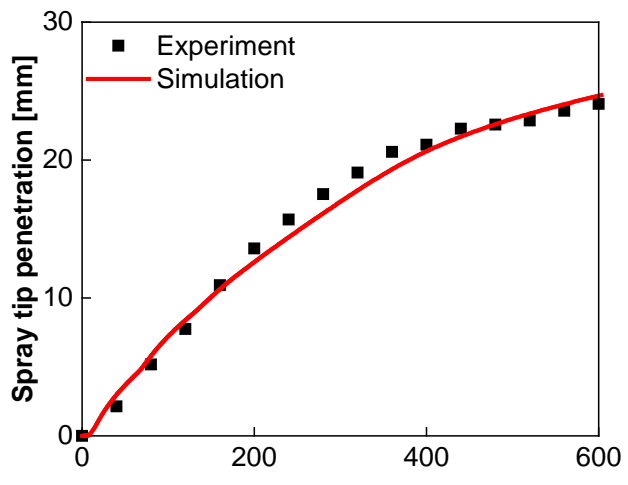

ASOI Time $[\mu \mathrm{s}]$

Fig. 6. Comparison of measured and predicted spray tip penetrations for the micro-pilot diesel

\subsection{Engine CFD model validation}

250 Natural gas is composed primarily of methane, but may also contain ethane, propane and

251 heavier hydrocarbons. Small quantities of nitrogen may also be found in the natural gas. Table 3

252 provides the composition of the 13A natural gas in Japan, which is the same as that in the

Table 3. Natural gas compositions in percent volume.

\begin{tabular}{cc}
\hline $\mathrm{CH}_{4}$ & $89.91 \%$ \\
$\mathrm{C}_{2} \mathrm{H}_{6}$ & $4.42 \%$ \\
$\mathrm{C}_{3} \mathrm{H}_{8}$ & $4.61 \%$ \\
$\mathrm{n}-\mathrm{C}_{4} \mathrm{H}_{10}$ & $0.51 \%$ \\
$\mathrm{i}-\mathrm{C}_{4} \mathrm{H}_{10}$ & $0.45 \%$ \\
$\mathrm{i}-\mathrm{C}_{5} \mathrm{H}_{12}$ & $0.03 \%$ \\
$\mathrm{~N}_{2}$ & $0.07 \%$ \\
\hline
\end{tabular}

Prior to optimization of the engine operating conditions and the combustion bowl geometry,

257 the 3D CFD engine simulation model must be validated against the experimental results,

258 including the cylinder pressure trace, the rate of heat release, and the exhaust gas emissions. 
260 (AHRR) between the experiment and simulation. As shown in this figure, the predicted pressure

261 history and AHRR agrees reasonably well with the experimental results.

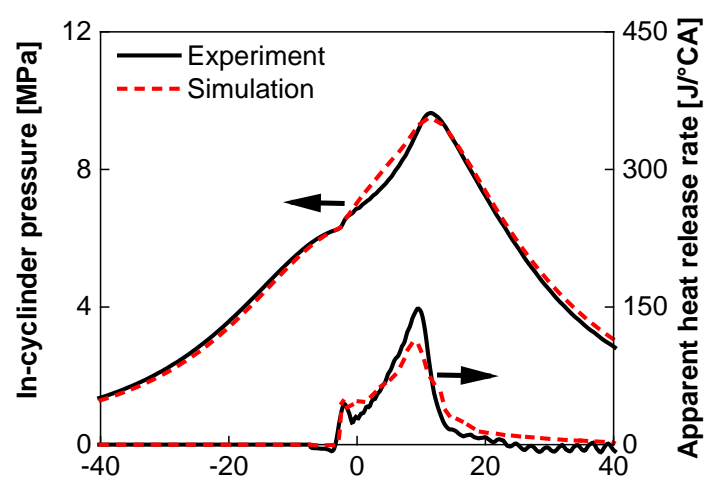

Crank angle [ $\left.{ }^{\circ} \mathrm{ATDC}\right]$
Fig. 7. Model validation for in-cylinder pressure history and apparent heat release rate (IMEP=8.0 bar, $n=1200 \mathrm{rpm}, V_{D F}=4.0 \times 10^{-3} \mathrm{ml} /$ cycle, $\Phi_{N G}=0.513$ ).

the experimental emissions in Figure 8. A reasonably well agreement between the simulation and experimental data is also achieved for the $\mathrm{HC}$ and $\mathrm{CO}$ emissions. A relatively large deviation of the calculated result from the experimental result is observed for the NOx emissions. Since the objective of this study is to reduce HC and CO emissions, only extended Zel'dovich NOx mechanism (i.e. Thermal NOx) was employed in the simulation to reduce the computation cost. The decreased combustion temperature in the lean operation of MPII engine would make it more significant the prompt NOx which produced at relatively low temperature. That could be the reason for the large deviations of NOx calculation, but further investigations are needed to clarify this issue. Since the primary target of this study is to reduce the HC and CO emissions by optimization of the combustion chamber geometry, the calibrated simulation models are believed to be effective to do the work in this study. 


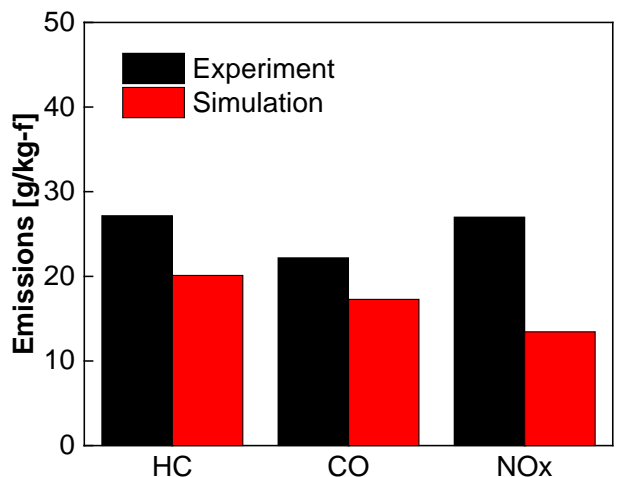

\section{Model-based optimization methodology}

Fig. 8. Comparisons of emissions between simulation and experiments (IMEP=8.0 bar, $n=1200 \mathrm{rpm}, V_{D F}=4.0 \times 10^{-3} \mathrm{ml} /$ cycle, $\Phi_{N G}=0.513$ ).

\subsection{Parameterization of combustion chamber geometry}

In order to obtain the variable combustion chamber geometries, the outline of the piston describe the piston bowl geometry [33-35], as shown in Figure 9. In this work, compression ratio was kept constant for all the cases with varying $\mathrm{R}_{\text {bowl }}$. Therefore, the volume of the piston bowl, cylinder bore, engine stroke, and the height of squish zone are not changed during optimization.

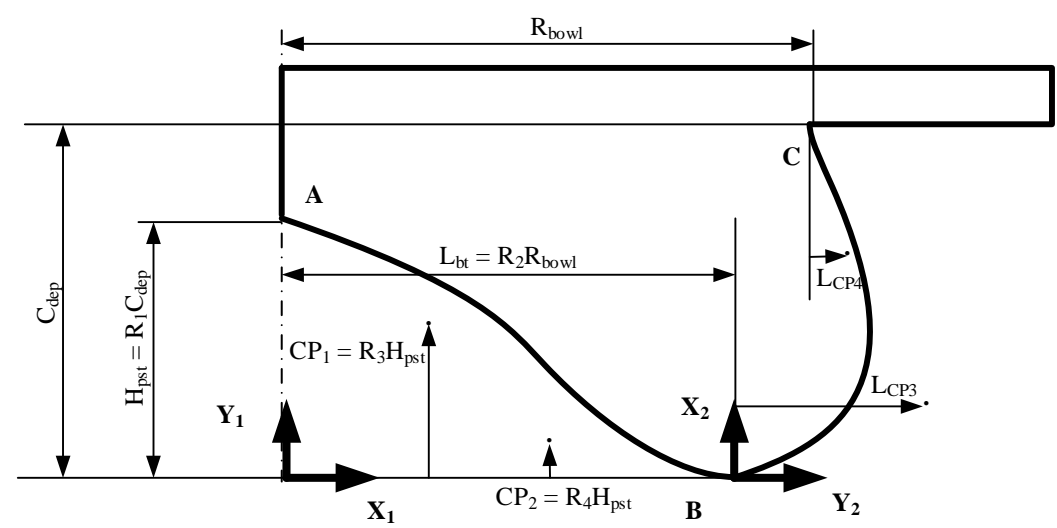

Fig. 9. The parameterized combustion chamber geometry by two Bezier functions. follows: 


$$
\left\{\begin{array}{l}
X_{1}(t)=t \times L_{b t} \\
Y_{1}(t)=(1-t)^{3} H_{p s t}+3(1-t)^{2} t C P_{1}+3(1-t) t^{2} C P_{2} \\
X_{2}(t)=t \times C_{d e p} \\
Y_{2}(t)=3(1-t)^{2} t L_{C P 3}+3(1-t) t^{2} L_{C P 4}+t^{3}\left(R_{b o w l}-L_{b t}\right)
\end{array}\right.
$$

where $t \in[0,1]$ 。

For the sake of simplicity $\mathrm{R}_{3}$ and $\mathrm{R}_{4}$ are 1.1 and 0 , respectively, for all the cases in the present study.

\subsection{Design of experiment and meta-modeling}

The optimization algorithm is sometimes coupled with the full model (i.e., the sophisticated CFD simulation model in this study) to explore the total available design space [36, 37].

However, it will lead to the excessive consumption of the computational time and efforts.

Therefore, in this work, the CFD simulation model of the MPII natural gas engine was replaced by the high-fidelity meta-model to engage the optimization procedure.

Based on the combination of innovative space-filling criteria and specialized optimization schemes [38, 39], the optimized Latin hypercube sampling strategy (OLHS), served as a kind of excellent technique of Design of Experiment (DOE), was employed in the present study.

Compared to the conventional Latin hypercube sampling method, OLHS, as a more efficient sampling strategy, requires fewer sample points and achieves a specific level of accuracy [40]. The design variables and corresponding ranges are listed in Table 4.

Table 4. Design variables and corresponding ranges.

\begin{tabular}{cc}
\hline Design variable & Range \\
\hline $\mathrm{C}_{\text {dep }}$ & $14-25 \mathrm{~mm}$ \\
$\mathrm{R}_{1}$ & $0.3-0.7$ \\
$\mathrm{R}_{2}$ & $0.5-0.8$
\end{tabular}




\begin{tabular}{cc}
$\mathrm{L}_{\mathrm{CP} 3}$ & $10-20 \mathrm{~mm}$ \\
$\mathrm{~L}_{\mathrm{CP} 4}$ & $-10-10 \mathrm{~mm}$ \\
Injection timing & $-15--5^{\circ} \mathrm{CA}$ ATDC \\
Included spray angle & $140^{\circ}-170^{\circ}$ \\
\hline
\end{tabular}

312

313 In this study, a total of 80 sampling points were generated by the OLHS method. Figure 10

314 depicts the typical combustion chamber geometries, including the re-entrant, shallow bowl,

315 open-crater and deep bowl types based on the proposed sampling points. It means that the

316 proposed methodology is capable of creating most of the bowl shapes considered in practical

317 diesel engines.

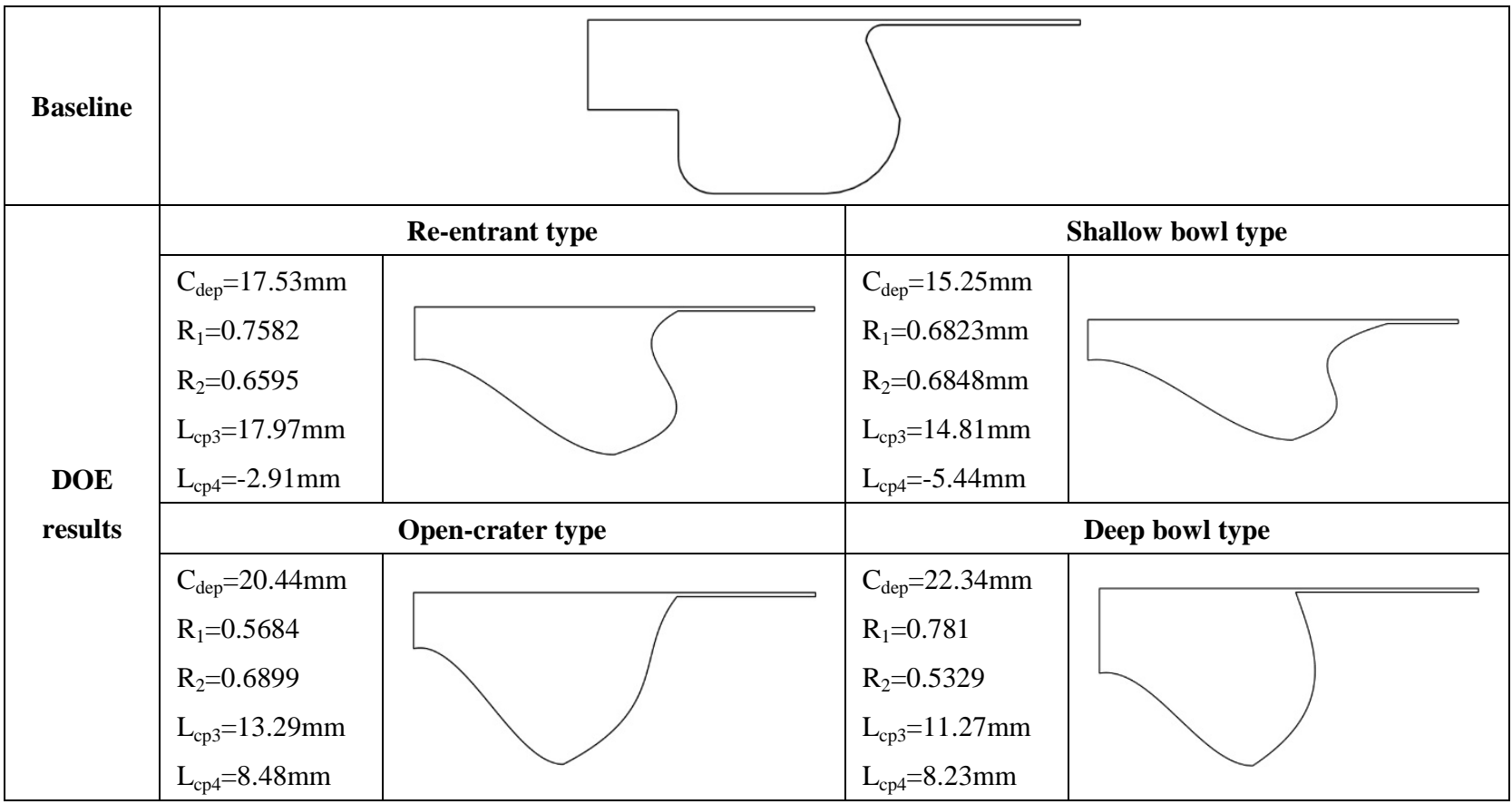

Fig. 10. Typical combustion chamber geometries from 80 sampling points generated by the

323 response surface method (RSM) [42] and artificial neural networks (ANN) method [43],

324 respectively. Here, Root Mean Square Error (RMSE) and Maximum Absolute Error (MAX) 
served as commonly used validation metrics for the different meta-models are listed in Table 5

[44]. Accordingly, the results show that the Kriging method can provide a higher predicted procedure.

Table 5. Validation metrics for different meta-models.

\begin{tabular}{ccccccc}
\hline \multirow{2}{*}{ Meta-model } & \multicolumn{2}{c}{ Kriging } & \multicolumn{2}{c}{ RSM } & \multicolumn{2}{c}{ ANN } \\
& RMSE & MAX & RMSE & MAX & RMSE & $M A X$ \\
\hline Gross indicated thermal efficiency $\eta_{i}(\%)$ & 0.120 & 0.203 & 0.342 & 0.650 & 0.210 & 0.419 \\
HC emissions (g/kg-f) & 0.197 & 0.215 & 0.410 & 0.722 & 0.307 & 0.805 \\
CO emissions (g/kg-f) & 0.181 & 0.216 & 0.269 & 0.509 & 0.250 & 0.492 \\
NOx emissions (g/kg-f) & 0.102 & 0.213 & 0.201 & 0.458 & 0.304 & 0.775 \\
\hline
\end{tabular}

\subsection{Multi-objective optimization for chamber geometry}

In the present study, the optimization objectives were set to minimize the $\mathrm{HC}$ and CO pressure rise $(d P / d \theta)_{\max }$ were treated as the constraint conditions, as shown in Equation (2):

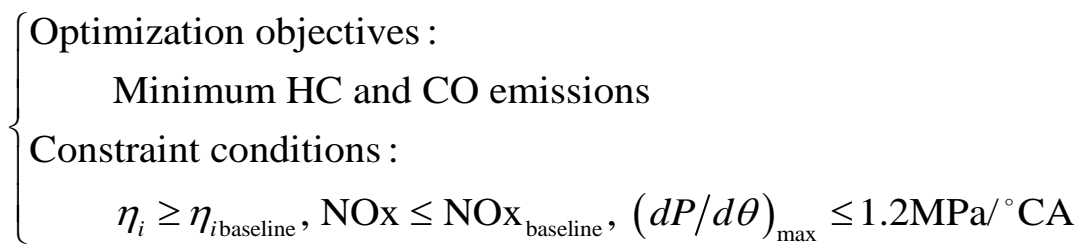

where $\eta_{\text {ibaseline }}$ and $\mathrm{NOx}_{\text {baseline }}$ are respectively the gross indicated thermal efficiency and NOx emissions of the engine in the experiments.

Therefore, the multi-objective evolutionary algorithm (MOEA) based on the principles of natural evolutionary in biological systems [44] was used to resolve the proposed design strategy and diversity preserving mechanism was adopted in this work. 


\section{Results and discussion}

\subsection{Optimal results of the combustion chamber geometry}

The optimal results of the design objectives and constraint conditions obtained by the multi-objective optimization algorithm NSGA-II are listed in Table 6. After optimization, the HC emissions has been substantially decreased from 16.38 g/kg-f to 7.13 g/kg-f. In addition, another optimal objective, the CO emissions, has a reduction of about 33.55\%. Simultaneously, the NOx emissions, gross indicated thermal efficiency $\eta_{i}$ have been slightly improved, and the maximum rate of pressure rise $(d P / d \theta)_{\max }$ have been slightly increased.

Table 6. The comparison between baseline case and optimum case.

\begin{tabular}{c|cccc}
\hline \multicolumn{2}{c}{ Item } & Baseline & Optimum & Variation \\
\hline \multirow{2}{*}{ Objectives } & HC emissions (g/kg-f) & 16.38 & 7.13 & $-56.47 \%$ \\
& CO emissions (g/kg-f) & 14.07 & 9.35 & $-33.55 \%$ \\
\hline \multirow{3}{*}{ Constraints } & NOx emissions (g/kg-f) & 10.96 & 10.82 & $-1.28 \%$ \\
& Gross indicated thermal efficiency (\%) & 42.77 & 43.31 & $+1.26 \%$ \\
& Maximum rate of pressure rise (MPa/ $\left./{ }^{\circ} \mathrm{CA}\right)$ & 1.17 & 1.19 & $+1.71 \%$ \\
\hline
\end{tabular}

Figure 11 illustrates the optimal results of design variables and the corresponding from $16.70 \mathrm{~mm}$ to $24.37 \mathrm{~mm}$, which is $45.93 \%$ larger than its original depth. However, the inlet diameter of the combustion chamber $\mathrm{R}_{\text {bowl }}$ is reduced from $27.70 \mathrm{~mm}$ to $25.87 \mathrm{~mm}$. As a result,

357 the surface area/volume ratio of optimal combustion chamber is $0.185 \mathrm{~mm}^{-1}$, which is $11.06 \%$

358 less than that of the baseline case. As well-known, it is beneficial that the less surface area/volume ratio will decrease the heat transfer loss during the engine operating process, 
$157.47^{\circ}$ in comparison to the baseline case.

$$
\begin{aligned}
& \mathrm{C}_{\text {dep }}=24.37 \mathrm{~mm} \\
& \mathrm{R}_{1}=0.6975 \\
& \mathrm{R}_{2}=0.6949 \\
& \mathrm{~L}_{\mathrm{cp} 3}=16.08 \mathrm{~mm} \\
& \mathrm{~L}_{\mathrm{cp} 4}=4.68 \mathrm{~mm} \\
& \text { Injection timing }=-8.20^{\circ} \mathrm{CA} \text { ATDC } \\
& \text { Included spray angle }=157.47^{\circ}
\end{aligned}
$$

Fig. 11. Optimal design variables and the corresponding combustion chamber geometry based on NSGA- II multi-objective optimization algorithm. heat release of the baseline and optimum cases are shown together. It can be seen that the high temperature reaction of optimum case started slightly earlier than that of the baseline case. As a result, the optimal CA50 (crank angle of 50\% accumulative heat released) combustion phasing for the 8.0 bar IMEP operation is found to be $6.65^{\circ} \mathrm{CA}$ ATDC. Compared to the original 8.50ㄷA ATDC@CA50, the optimal combustion phasing is closer to the top dead center of the

372 piston, leading to the higher degree of constant volume heat release during the combustion

373 process. Combined with the less surface area/volume ratio, the fuel economy of optimum case

374 will be further improved. In addition, as to the optimum case, the maximum value of AHRR represents a $12.49 \%$ reduction in comparison to the baseline case. However, the peak in-cylinder pressure through the optimization has been slightly increased from 9.45 MPa to 9.94 MPa. That means the thermal efficiency of the MPII natural gas engine is not deteriorated for the optimum case. 


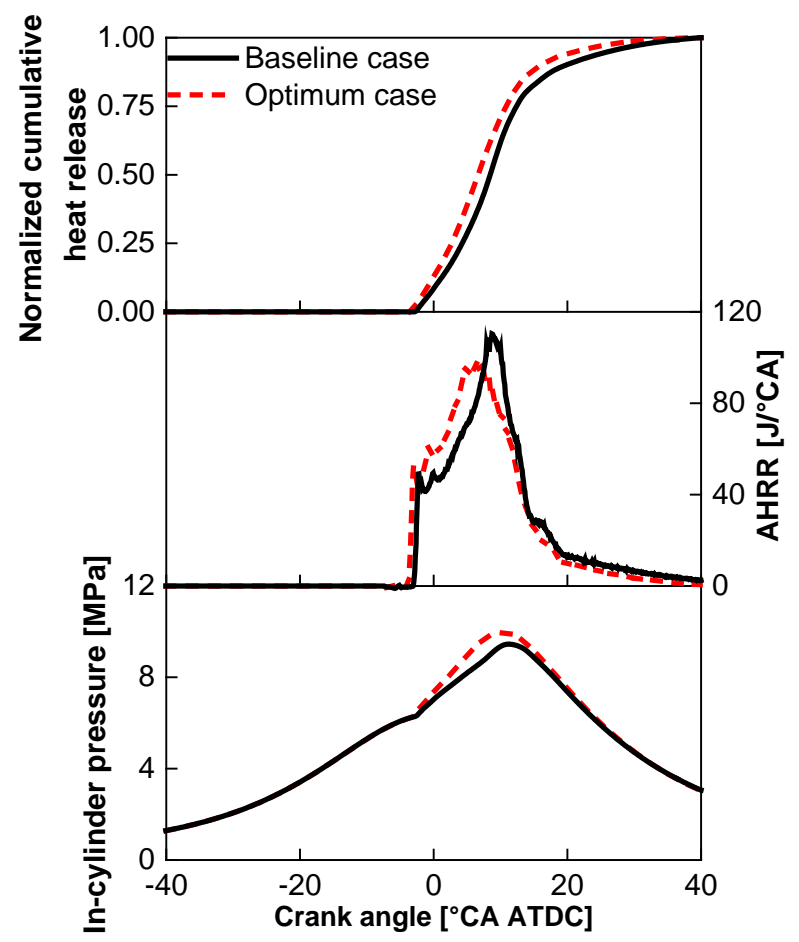

Fig. 12. Comparisons of the in-cylinder pressure history, apparent heat release rate and normalized cumulative heat release between optimum case and baseline case.

384 with the crank angle for the optimum and baseline cases seem to be similar. However, the

385 production amount of HC/CO emissions for the optimum case are significantly reduced at the

386 same crank angle position after top dead center compared to the baseline. Furthermore, the NOx

387 emission of the optimum case is comparable to that of the baseline case, as shown in Figure 388 13(c).
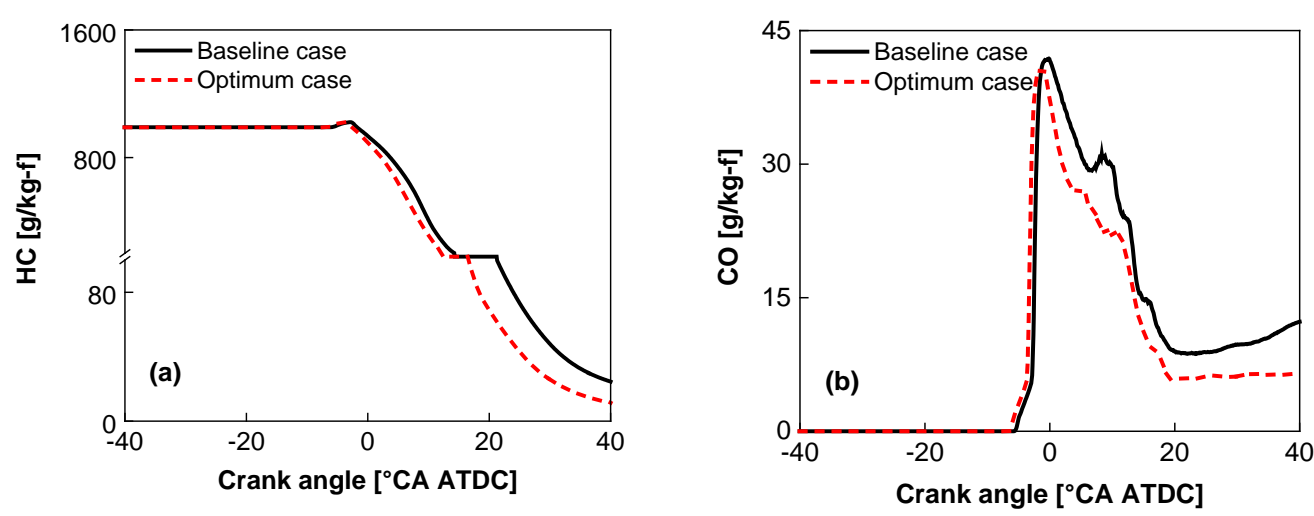


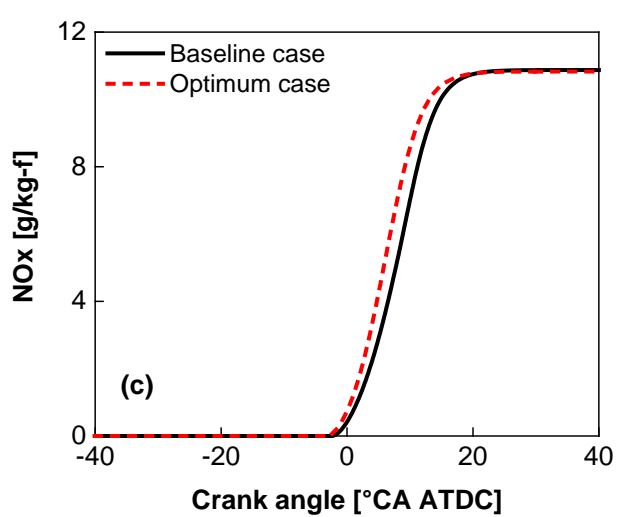

Fig. 13. Comparisons of the exhaust gas emission characteristics between optimum and baseline cases.

CFD simulations of the MPII natural gas engine with the diesel fuel injection timing swept from -10 to $-5^{\circ} \mathrm{CA}$ ATDC under the same conditions as in Figure 13 were conducted, the results are depicted in Figure 14. The black star represents the level of baseline case using $-7.30^{\circ} \mathrm{CA}$ ATDC injection timing, the red star denotes the optimum case with $-8.20^{\circ} \mathrm{CA}$ ATDC injection timing, and the black and red curves indicate the data trend with the injection timing sweep. With fixed injection timing, compared to the baseline case, both the HC, CO and NOx emissions are lower, and the thermal efficiency is slightly higher for the optimized combustion chamber. As the injection timing of diesel fuel is advanced, though the $\mathrm{HC}$ and $\mathrm{CO}$ emissions decrease and the gross indicated thermal efficiency increase, the NOx emissions and maximum rate of pressure rise also increase. As a result of the NOx emissions and $1.2 \mathrm{MPa} /{ }^{\circ} \mathrm{CA}$ maximum rate of pressure rise constraints, the optimized result goes to the injection timing as shown by the red star in Figure 14. 

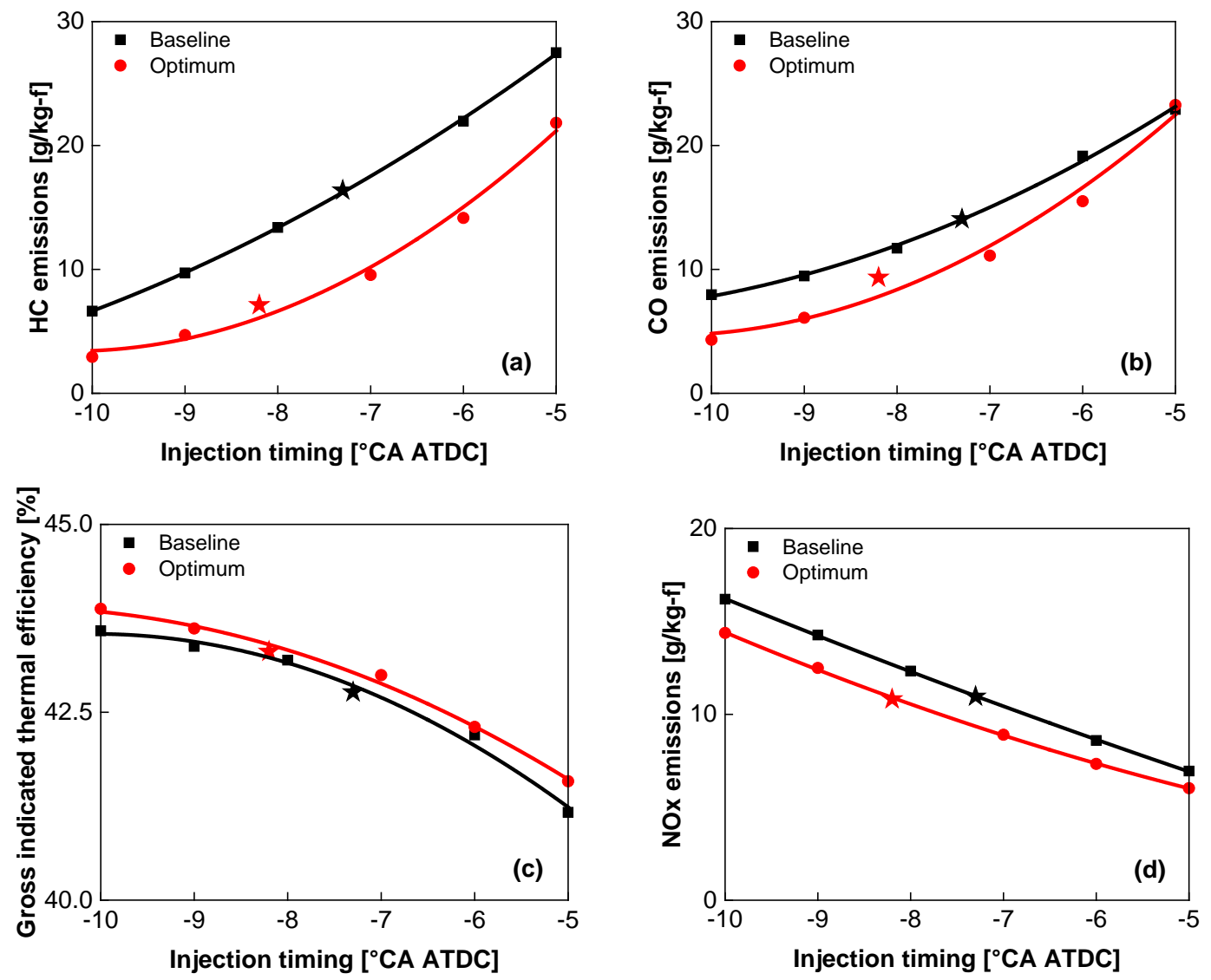

407

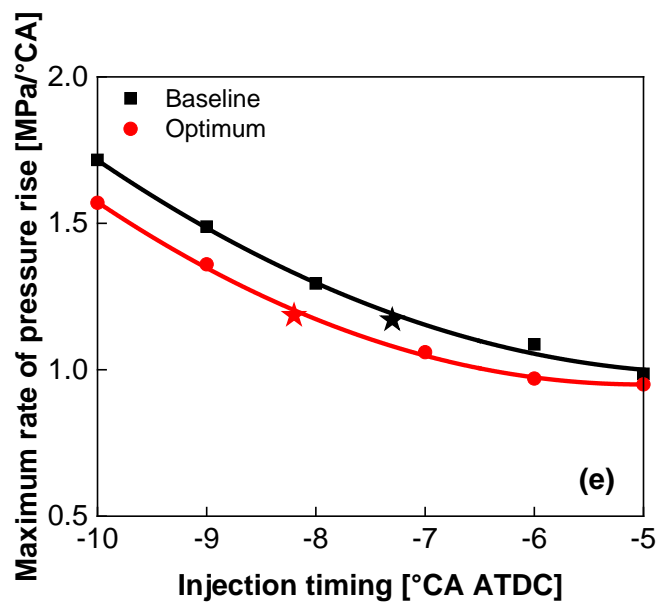

408

Fig. 14. Comparisons of exhaust emissions, thermal efficiency and maximum rate of pressure rise at injection timing sweep of short-pulsed diesel fuel. 
414 Figure 15 represents the in-cylinder distribution of the diesel fuel at the selected crank angles.

415 Since the injection amount of the short-pulsed diesel is small, the dilution process of diesel fuel

416 is proceeded quickly under the entrainment movement between the diesel spray and in-cylinder

417 ambient gas flow. As shown in Figure 15, after CA5, the diesel fuel concentration almost can't

418 be observed any more.

\section{Baseline}
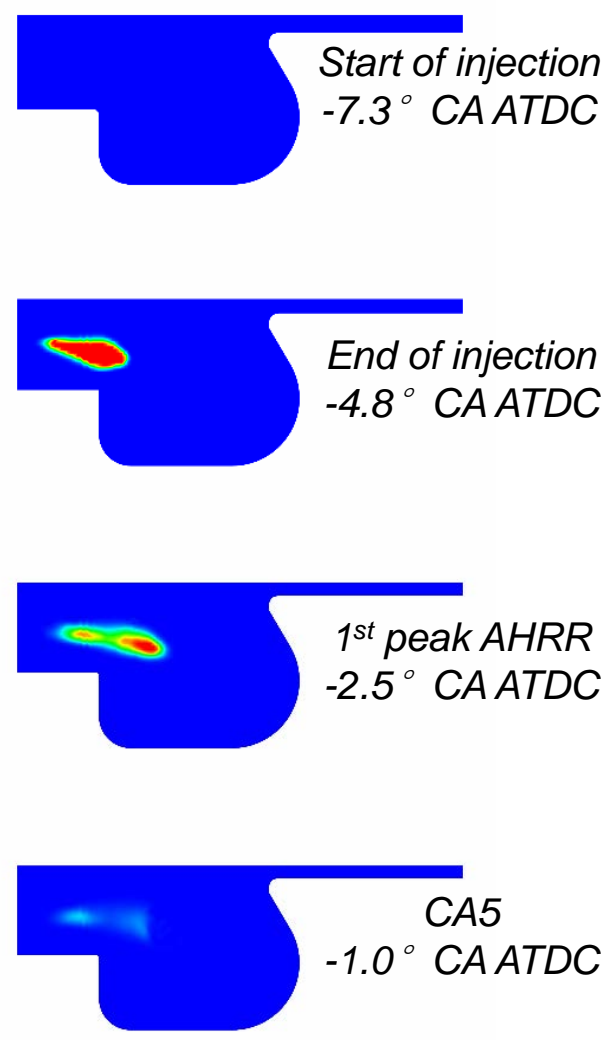

419

420

421

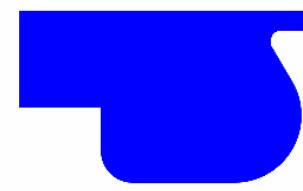

$2^{\text {nd }}$ peak $A H R R$ $8.5^{\circ}$ CA ATDC

\section{Optimum}
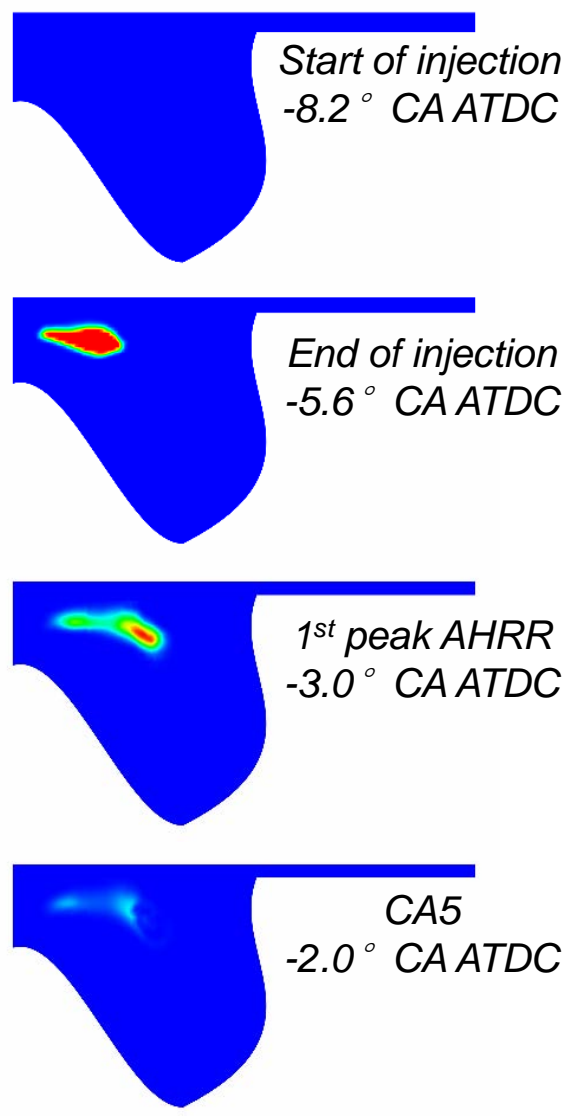

$2^{\text {nd }}$ peak AHRR

$6.5^{\circ}$ CA ATDC

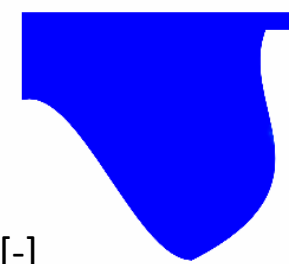

Diesel $[-]$

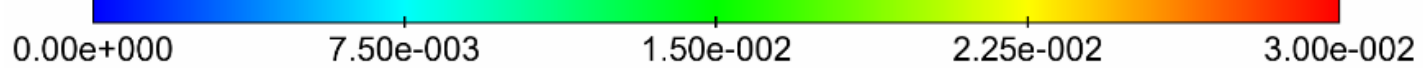

Fig. 15. Contour plots of diesel fuel mole fraction at selected crank angles. 
Figure 12. In this study, the equivalent ratio of natural gas is set to 0.513 , which will not produce the obvious soot emissions. Furthermore, the premixed combustion of diesel fuel help suppress the soot formation as well. That is the reasons why the amount of soot formed in the MPII natural gas engine was not discernable in the previous experimental study [13]. short-pulsed diesel spray. Then, the burning zone is rapidly expanded to the surrounding region of high reactivity that is comprised primarily of the mixture of diesel fuel and natural gas. Here whether the rapid expansion of the burning zone is attributed to a propagation of regular flame or a propagation of auto-ignition as suggested in the previous paper [13] is not clear, and further exploration are needed to clarify this issue in the future. As to the optimum case, the area of regions with temperature higher than $2200 \mathrm{~K}$ is comparable with that of the baseline case. That is the reasons why the NOx emissions were not deteriorated after the optimization. It is noteworthy that at the CA95, there are still some unburned end gases in the center of combustion

439 chamber of the baseline case besides the squish zone. In contrast, the unburned region of the 440 optimum case only exists in the squish zone, where there are larger area with the temperature 441 above $1700 \mathrm{~K}$. This would lead to reduced unburned HC and CO emissions, which will be depicted in details in Figure 17 and Figure 18. 


\section{Baseline}
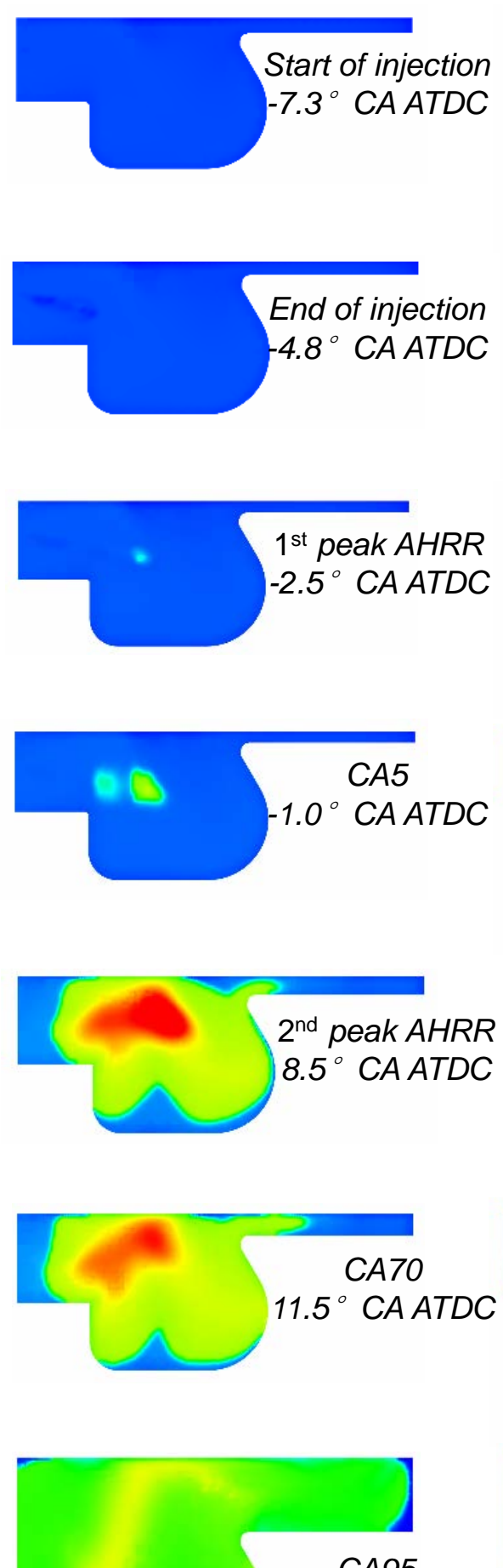

$26^{\circ}$ CA ATDC

\section{Optimum}
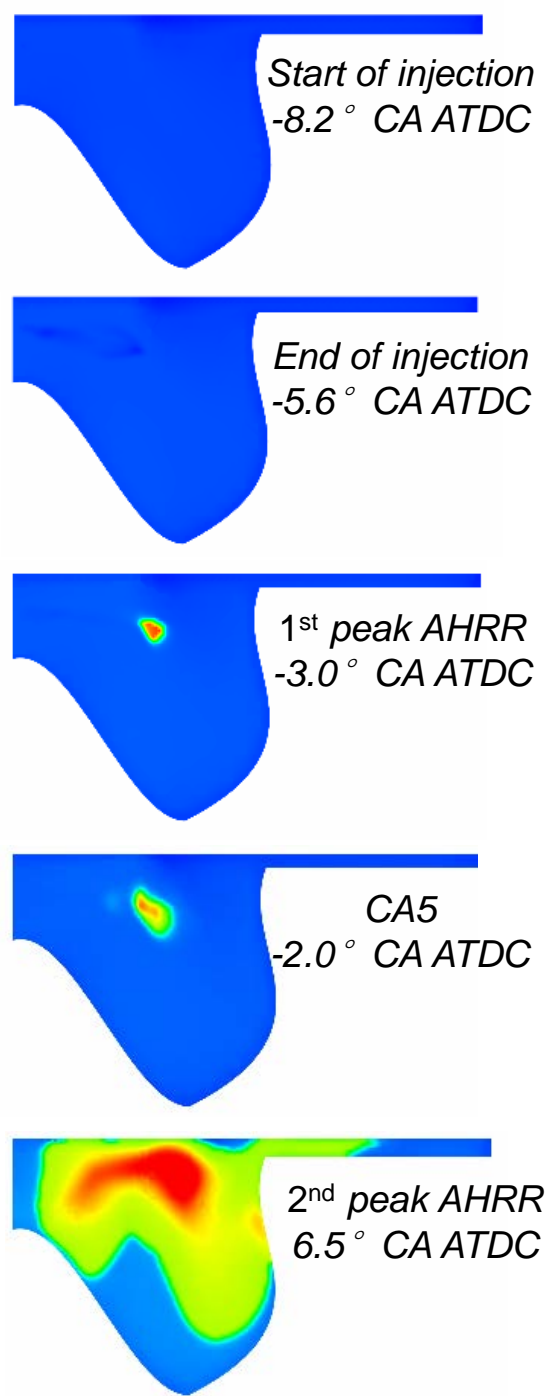

$2^{\text {nd }}$ peak AHRR $6.5^{\circ}$ CA ATDC
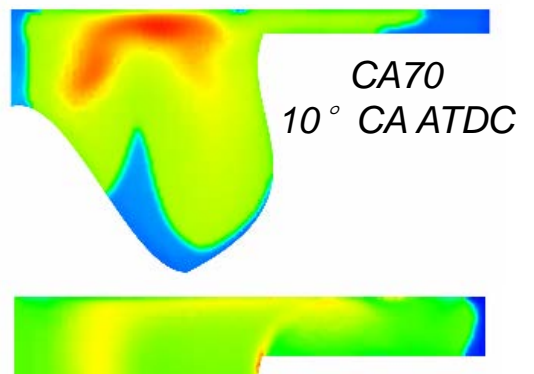

CA95

$21.5^{\circ} \mathrm{CA} A T D C$ 
446 the unburned $\mathrm{HC}$, which is multi-component mixture, is represented by $\mathrm{CH}_{4}$ as the major

447 component of the unburned HC. Initially, the natural gas (i.e., unburned HC) is entrained into the 448 diesel spray, then burned with the auto-ignition of the diesel fuel. Therefore, the HC emissions in 449 the MPII natural gas engine would stem primarily from the unburned region, as shown in Figure 450 17. However, the low temperature oxidation reaction of diesel fuel at the end of injection firstly 451 produces an amount of CO emissions. With the flame propagation, the CO emissions are 452 produced at the flame front, as depicted in Figure 18.

453 At the end of the combustion (i.e., CA95), there exists HC and CO in both the chamber 454 center and the squish zone in the baseline case. In comparison to the baseline case, only the 455 squish zone have some HC and CO emissions, and their occupied area is remarkably reduced. 


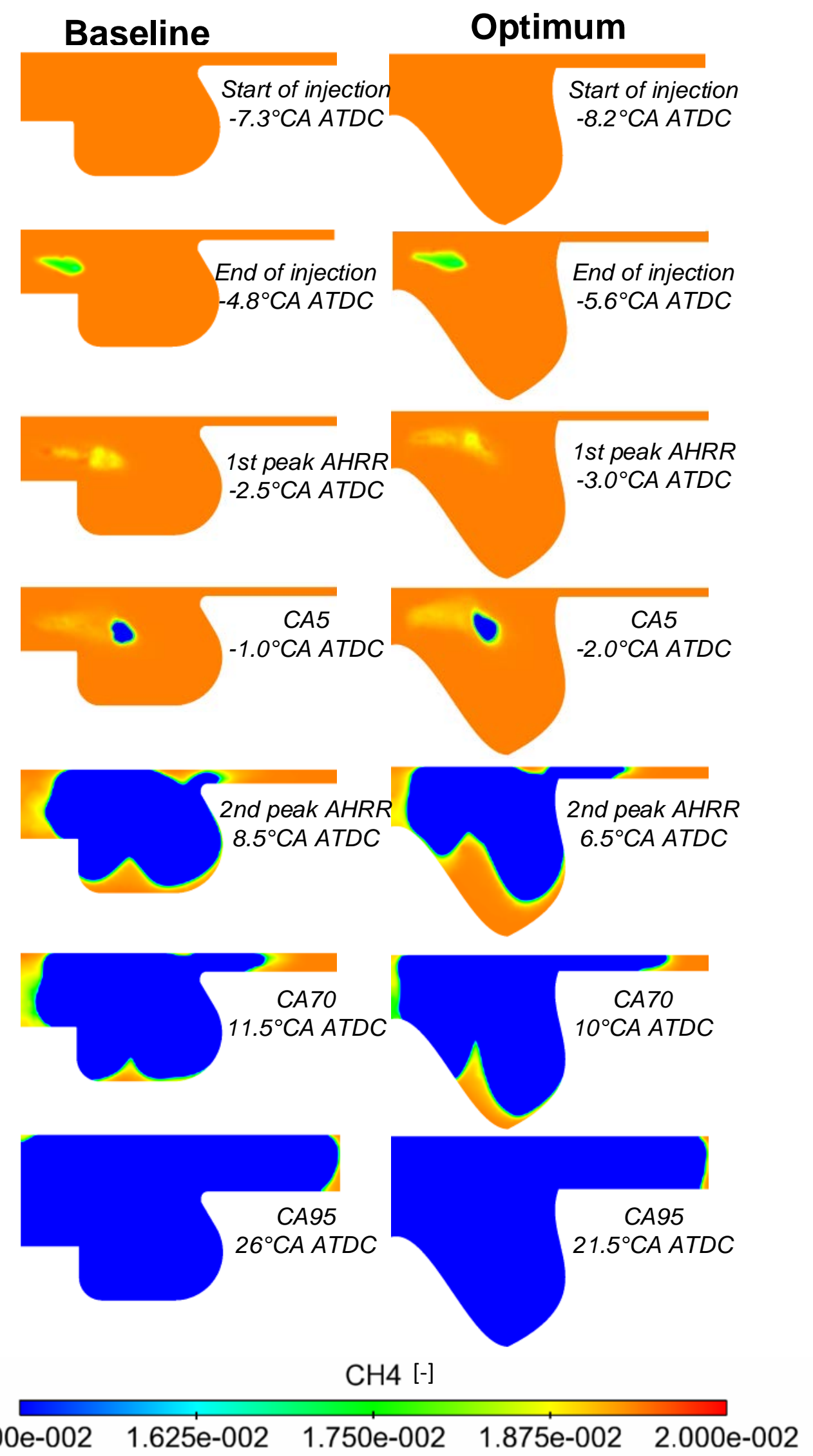

Fig. 17. Contour plots of the $\mathrm{CH}_{4}$ mole fraction at selected crank angles. 
Baseline
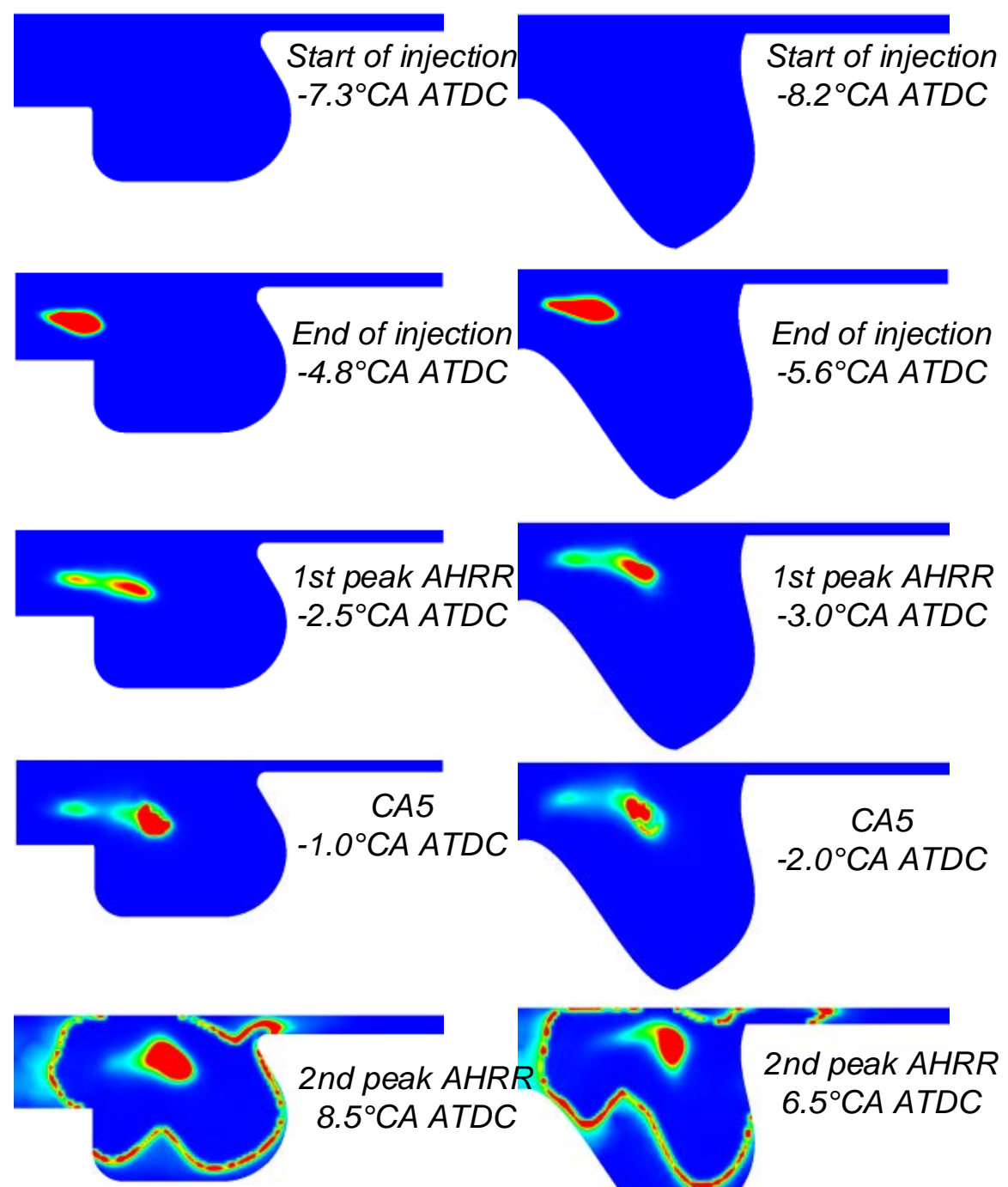

2nd peak AHRR $8.5^{\circ} \mathrm{CA} A T D C$

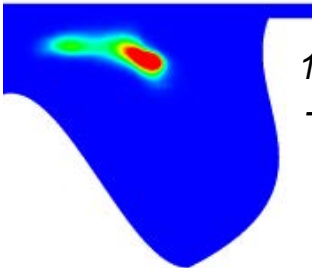

1st peak AHRR $-3.0^{\circ} \mathrm{CA} A T D C$

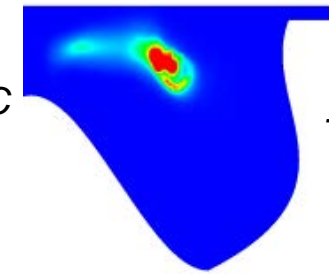

CA5

$-2.0^{\circ} \mathrm{CA} A T D C$

2nd peak AHRR $6.5^{\circ} \mathrm{CA} A T D C$
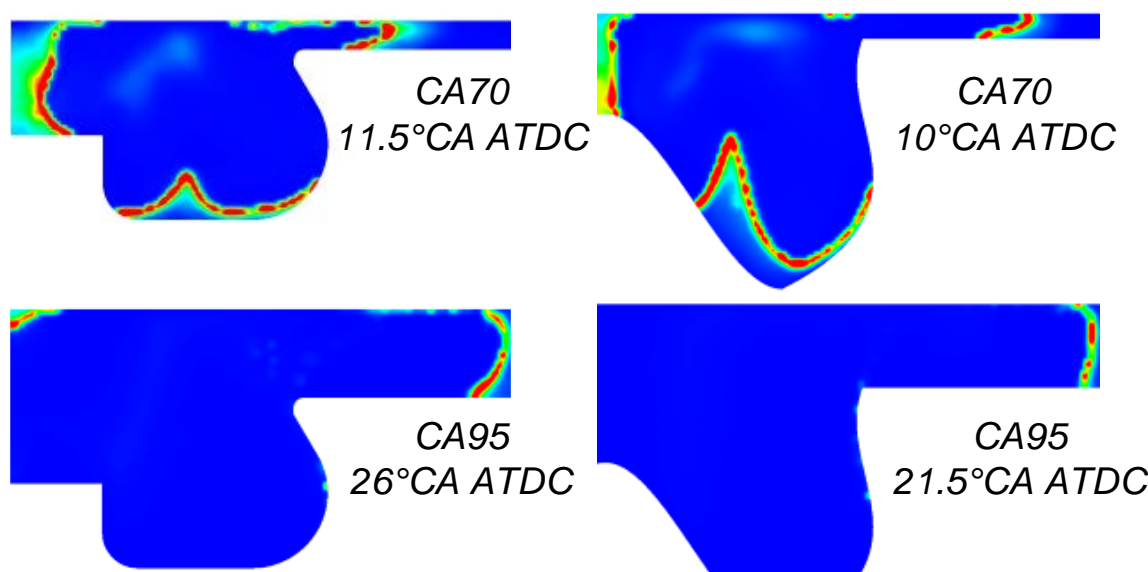

$0.00 \mathrm{e}^{+} 000 \quad 1.25 \mathrm{e}^{\prime}-003 \quad 2.50 \mathrm{e}-003 \quad 3.75 \mathrm{e}^{\prime}-003 \quad 5.00 \mathrm{e}-003$

Fig. 18. Contour plots of the $\mathrm{CO}$ mole fraction at selected crank angles. 
461 the flow field at the selected crank angles are shown in Figure 19. Here the color bar is

462 employed to represent the strength of flow field, the black thin arrows only denote the direction

463 of the in-cylinder flow and the primary flow structures are highlighted by the white thick arrow

464 in Figure 19. In the optimum case, there are two counter-rotating vortex structures at the leading

465 edge of the micro-pilot diesel spray. These vortex structures might help promote the fuel and

466 ambient air mixing. Before TDC, owing to the larger area of piston top land in the squish zone

467 for the optimum case, the squish flow as shown in the dashed box in Fig. 19 is apparently

468 stronger than that of the baseline case. Moreover, while there are a clockwise tumble flow in the

469 piston bowl for both cases, it is stronger in the optimum case than the baseline case. After TDC,

470 with the piston moving downward, the clockwise tumble flow carries the stronger squish flow

471 into the bottom region of the piston bowl and then moves toward the center region of the

472 chamber, resulting in stronger turbulence for the optimum case than the baseline case.

473 Meanwhile, the anti-squish flow toward the squish zone is enforced by the larger area of piston

474 top land in the squish zone for the optimum case, compared to the baseline case. As a

475 consequence, the in-cylinder kinetic energy in the optimum case is higher for almost the whole

476 combustion period, compared to the baseline case, as depicted in Figure 20. This could be the

477 reason why the $\mathrm{HC}$ and $\mathrm{CO}$ emissions are reduced by optimization of the combustion chamber

478 geometry. 


\section{Baseline}
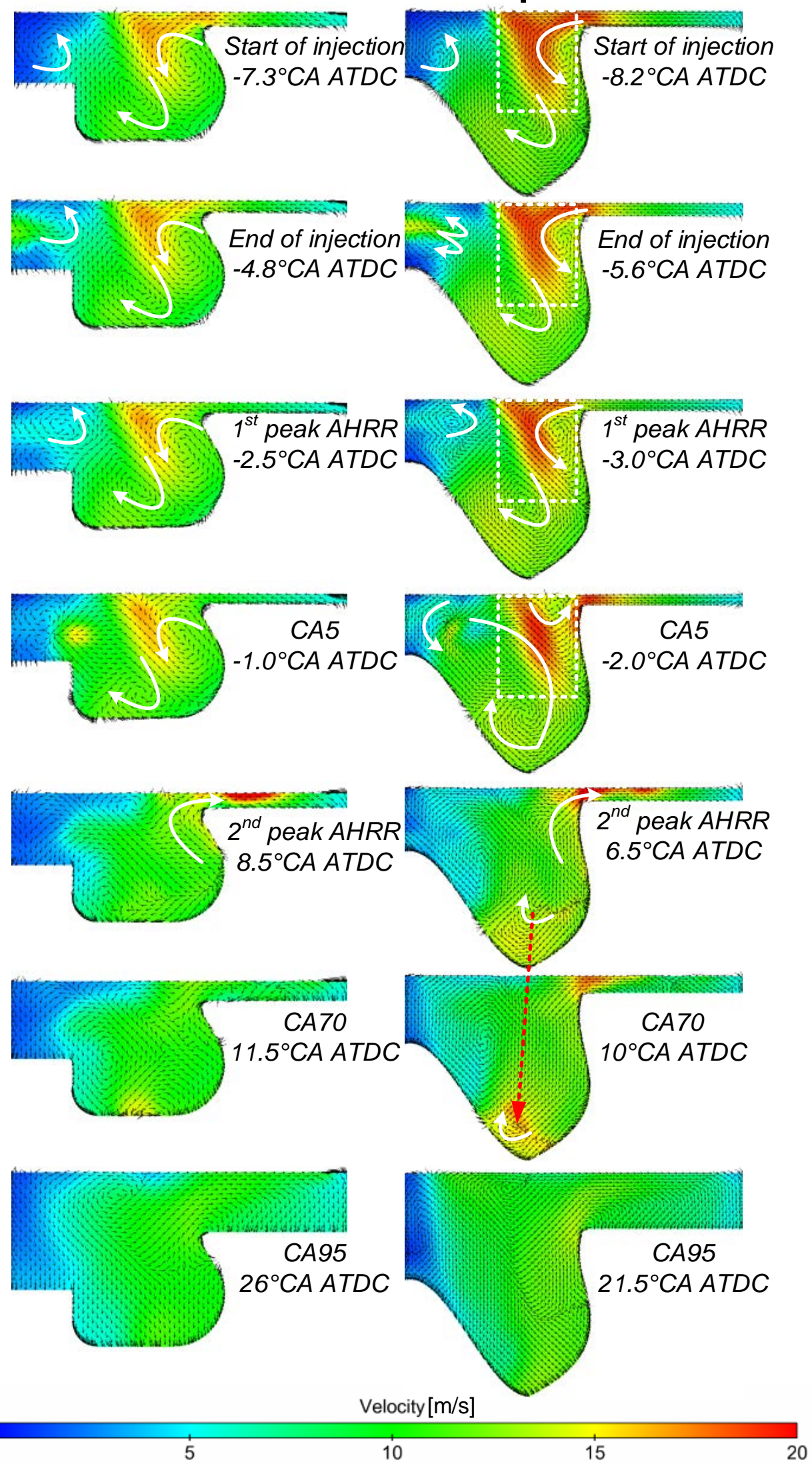

Fig. 19. The in-cylinder flow field at selected crank angles. 


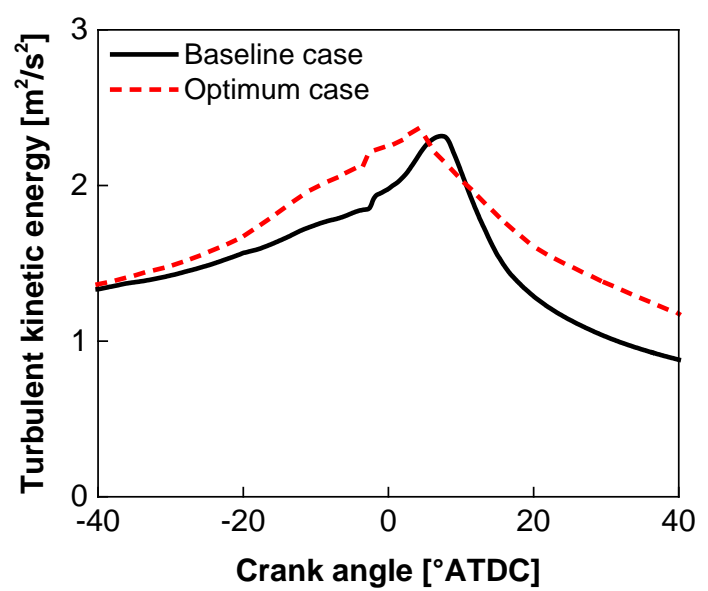

481

482

483

484

485

486

487

488

489

490

491

492

493

494

495

496

497

\section{Conclusions}

In the present study, optimization of the combustion chamber geometry and the engine operating conditions for natural gas engines with diesel micro-pilot-induced ignition were implemented using the NSGA- II multi-objective evolutionary algorithm, aiming at reductions in the $\mathrm{HC}$ and $\mathrm{CO}$ emissions and improvement in the combustion efficiency. The major results are summarized as follows:

- The computational results of the proposed CFD model agree reasonably well with the experimental results, and a variety of combustion chamber geometries can be generated by the parameterized Bezier functions.

- With the proposed optimization methodology based on the Kriging meta-model and optimized Latin hypercube sampling strategy, the HC and CO emissions are reduced by $56.47 \%$ and $33.55 \%$, respectively. The gross indicated thermal efficiency, the NOx emissions and the maximum rate of pressure rise, which were used as constraints in the optimization, are to some degree improved. 

514 acknowledged.

- Ignition occurs at the leading edge after end of the micro-pilot diesel injection, then the burning zone expands quickly over the highly reactive diesel and nature gas mixture. However, whether the auto-ignition or regular flame propagation dominates the process is still not clear, and further exploration is needed to clarify this issue in the future.

- The increased thermal efficiency is attributed to the smaller surface area/volume ratio and higher degree of constant volume heat release, while the slightly improved NOx and maximum rate of pressure rise could be due to the faster mixing by the micro-pilot diesel spray and ambient gas in the optimum case, compared to the baseline case.

- The greater tumble flow with the deep bowl and the stronger squish flow and anti-squish flow owing to the larger area of piston top land in the squish zone greatly enhance the in-cylinder turbulent kinetic energy, resulting in the reduced HC and CO emissions in the optimum case, compared to the baseline case.

\section{Acknowledgement}

The supports by the Natural Science Foundation of China (51276115 \& 91541104) and the Funding by SKL Ocean Engineering (GKZD010065\&GKZD010068) are gratefully

\section{References}

517 [1] Lamaris VT, Hountalas DT. A general purpose diagnostic technique for marine diesel

518 engines - application on the main propulsion and auxiliary diesel units of a marine vessel.

$519 \quad$ Energy Convers Manage 2010; 51(4): 740-53. 
[2] Hountalas DT. Prediction of marine diesel engine performance under fault conditions. Applied Thermal Engineering 2000; 20(18): 1753-83.

[3] Herdzik J. Emissions from marine engines versus IMO certification and requirements of tier 3. Journal of KONES 2011; 18: 161-7.

[4] Park SH, Lee CS. Applicability of dimethyl ether (DME) in a compression ignition engine as an alternative fuel. Energy Convers Manage 2014; 86: 848-63.

[5] Yousefi A, Biroukb M, Lawlerc B, Gharehghania A. Performance and emissions of a dual-fuel pilot diesel ignition engine operating on various premixed fuels. Energy Convers Manage 2015; 106: 322-36.

[6] Li T, Moriwaki R, Ogawa H, Kakizaki R, Murase M. Dependence of premixed low-temperature diesel combustion on fuel ignitability and volatility. International Journal of Engine Research 2012; 13(1): 14-27.

[7] Yang B, Wei X, Xi CX, Liu Y, Zeng K, Lai MC. Experimental study of the effects of natural gas injection timing on the combustion performance and emissions of a turbocharged common rail dual-fuel engine. Energy Convers Manage 2014; 87: 297-304.

[8] U.S. Energy Information Administration. International energy statistics. 2015. $<$ http://www.eia.gov/cfapps/ipdbproject/IEDIndex3.cfm?tid=3\&pid=3\&aid=1>. [accessed on 13. Dec. 2015].

[9] Cho HM, He BQ. Spark ignition natural gas engines - a review. Energy Convers Manage 2007; 48(2): 608-18.

[10]Liao SY, Cheng Q, Jiang DM, Gao J. Experimental study of flammability limits of natural gas - air mixture. Journal of Hazardous Materials 2005; 119(1-3): 81-4. 
542 [11]Kato K, Igarashi K, Masuda M, Otsubo K, et al. Development of engine for natural gas

$543 \quad$ vehicle. SAE technical paper 1999-01-0574; 1999.

544 [12] Reyes M, Tinaut FV, Giménez B, Pérez A. Characterization of cycle-to-cycle variations in a 545 natural gas spark ignition engine. Fuel 2015; 140(0): 752-61.

546 [13] Ogawa H, Zhao PL, Kato T, Shibata G. Improvement of combustion and emissions in a dual 547 fuel compression ignition engine with natural gas as the main fuel. SAE technical paper 2015-01-0863; 2015.

549

[14]Reitz RD, Duraisamy G. Review of high efficiency and clean reactivity controlled compression ignition (RCCI) combustion in internal combustion engines. Progress in Energy and Combustion Science 2015; 46(0): 12-71.

552

[15]Takahashi S, Goto S, Nakayama S, Nishi Y. Result in Service operation of 1.3MW micro-pilot gas engine, and its future development. CIMAC Congress; Paper No.146; 2004.

[16]Tsunoda A, Yamamoto T, Dexter S. Further development of advanced gas engine KU30GA (MACH-30A). CIMAC Kongress; Paper No. 120; 2004.

[17]Abdelaal MM, Hegab AH. Combustion and emission characteristics of a natural gas-fueled diesel engine with EGR. Energy Convers Manage 2012; 64: 301-12.

[18]Papagiannakis RG, Hountalas DT. Combustion and exhaust emission characteristics of a dual fuel compression ignition engine operated with pilot Diesel fuel and natural gas. Energy emissions characteristics of a CNG/diesel dual fuel engine with optimized pilot injection timing. Applied Energy 2013; 110: 201-6. 
564 [20] Ishiyama T, Jeongho K, Yutaka O, Takahiro S. Improvement of performance and reduction

565 of exhaust emissions by pilot-fuel-injection control in a lean-burning natural-gas dual-fuel

$566 \quad$ engine. SAE Int. J. Fuels Lubr. 2011; 5(1): 243-53.

567 [21]Naber JD, Siebers DL. Effects of gas density and vaporization on penetration and dispersion 568 of diesel sprays. SAE technical paper 1996-02-01; 1996.

569 [22]Smith GP, Golden DM, Frenklach M, Moriarty NW, Eiteneer B, Goldenberg M, Lissianski

570 VV. GRI-Mech 3.0. 1999. http://combustion.berkeley.edu/gri-mech/. [accessed on 13. Dec.

$5712015]$.

572 [23]Farrell JT, Cernansky NP, Dryer FL, Law CK, Friend DG, Hergart CA, McDavid RM, Patel

573 AK, Mueller CJ, Pitsch H. Development of an experimental database and kinetic models for $574 \quad$ surrogate diesel fuels. SAE technical paper 2007-01-0201; 2007.

575 [24]Han Z, Reitz RD. Turbulence modeling of internal combustion engines using RNG $\kappa-\varepsilon$

576 models. Combustion Science and Technology 1995; 106(4-6): 267-95.

577 [25]Kong SC, Han Z, Reitz RD. The development and application of a diesel ignition and 578 combustion model for multidimensional engine simulation. SAE technical paper 950278; $579 \quad 1995$.

580 [26]Kong SC, Marriott CD, Reitz RD, Christensen M. Modeling and experiments of HCCI 581 engine combustion using detailed chemical kinetics with multidimensional CFD. SAE 582 technical paper 2001-01-1026; 2001.

583 [27]Schmidt DP, Rutland CJ. A new droplet collision algorithm. Journal of Computational $584 \quad$ Physics 2000; 164(1): 62-80. 
585

586

587

588

589

590
[28]Amsden AA, O’Rourke PJ, Butler TD. KIVA-II: a computer program for chemically reactive flows with sprays. Los Alamos National Laboratory Report No. LA-11560-MS; 1989.

[29]O’Rourke PJ, Amsden AA. A spray/wall interaction submodel for the KIVA-3 wall film model. SAE technical paper 2000-01-0271; 2000.

[30]Woschni G. A universally applicable equation for the instantaneous heat transfer coefficient in the internal combustion engine. SAE technical paper 670931; 1967.

[31]Patterson M, Kong S, Hampson G, Reitz R. Modeling the effects of fuel injection characteristics on diesel engine soot and NOx emissions. SAE technical paper 940523; 1994.

[32]Schmitt T, Méry Y, Boileau M, Candel S. Large-Eddy Simulation of oxygen/methane flames under transcritical conditions. Proceedings of the Combustion Institute 2011; 33(1): 1383-90.

[33]Park SW. Optimization of combustion chamber geometry for stoichiometric diesel combustion using a micro genetic algorithm. Fuel Processing Technology 2010; 91(11): $1742-52$

[34] Shi Y, Reitz RD. Assessment of optimization methodologies to study the effects of bowl geometry, spray targeting and swirl ratio for a heavy-duty diesel engine operated at high-load. SAE Int. J. Engines 2008; 1(1): 537-57.

[35]Park S. Optimization of combustion chamber geometry and engine operating conditions for compression ignition engines fueled with dimethyl ether. Fuel 2012; 97(0): 61-71. 
605 [36]Ge HW, Shi Y, Reitz RD, Wickman D, Willems W. Engine development using

606 multi-dimensional CFD and computer optimization. SAE technical paper 2010-01-0360;

6072010.

608 [37]Rajabi MM, Ataie-Ashtiani B, Janssen H. Efficiency enhancement of optimized Latin

609 hypercube sampling strategies: application to Monte Carlo uncertainty analysis and

610 meta-modeling. Advances in Water Resources 2015; 76: 127-39.

611 [38] Wołoszyn J, Gołaś A. Sensitivity analysis of efficiency thermal energy storage on selected

612 rock mass and grout parameters using design of experiment method. Energy Convers

$613 \quad$ Manage 2014; 87: 1297-304.

614 [39]Park J, Lee KS, Kim MS, Jung D. Numerical analysis of a dual-fueled CI (compression

615 ignition) engine using Latin hypercube sampling and multi-objective Pareto optimization.

$616 \quad$ Energy 2014; 70: 278-87.

617 [40]Monger SH, Morgan ER, Dyreson AR, Acker TL. Applying the Kriging method to

618 predicting irradiance variability at a potential PV power plant. Renewable Energy 2016; 86:

$619 \quad 602-10$

620 [41]Abbaszadeh K, Alam FR, Saied SA. Cogging torque optimization in surface-mounted

621 permanent-magnet motors by using design of experiment. Energy Convers Manage 2011;

$622 \quad$ 52(10): 3075-82.

623 [42]Piloto-Rodríguez R, Sánchez-Borroto Y, Lapuerta M, Goyos-Pérez L, Verhelst S. Prediction

624 of the cetane number of biodiesel using artificial neural networks and multiple linear

625 regression. Energy Convers Manage 2013; 65: 255-61. 
626 [43] Shan S, Wang GG. Survey of modeling and optimization strategies to solve

627 high-dimensional design problems with computationally-expensive black-box functions.

$628 \quad$ Structural and Multidisciplinary Optimization 2010; 41(2): 219-41.

629 [44]Marler RT, Arora JS. Survey of multi-objective optimization methods for engineering.

$630 \quad$ Structural and Multidisciplinary Optimization 2004; 26(6): 369-95.

631 [45]Coello CAC. Evolutionary multi-objective optimization: a historical view of the field. IEEE

632 Computational Intelligence Magazine 2006; 1(1): 28-36.

633 [46]Deb K, Pratap A, Agarwal S, Meyarivan T. A fast and elitist multi-objective genetic

634 algorithm: NSGA-II. IEEE Transactions on Evolutionary Computation 2002; 6(2): 182-97. 